\title{
Pharmacology of Retinotectal Transmission in the Goldfish: Effects of Nicotinic Ligands, Strychnine, and Kynurenic Acid
}

\author{
Ronald B. Langdon a and John A. Freeman \\ Departments of Cell Biology and Ophthalmology, Vanderbilt University School of Medicine, Nashville, Tennessee 37232
}

The goal of this study was to evaluate different neurotransmitters and their receptors that might be involved in retinotectal transmission in the goldfish. Sections of tectum were isolated and maintained in vitro while pharmacological agents were administered via the tissue bath. Field potentials were elicited by electrical stimulation of the optic nerve and recorded at $\mathbf{5 0} \mu \mathrm{m}$ depth intervals, and profiles of current source densities (CSDs) were computed from the second spatial derivatives of these potentials. The preparations were treated with low $\left[\mathrm{Ca}^{2+}\right] /$ high $\left[\mathrm{Mg}^{2+}\right]$ media, various cholinergic agonists and antagonists, eserine, strychnine, or kynurenic acid, via the tissue bath. Prior to treatment, depth profiles of these in vitro field potentials and CSDs closely resembled those previously reported in vivo, including 2 prominent sink-source pairs with their sinks in the superficial optic neuropil, followed by a smaller and more prolonged sink-source pair of opposite polarity. These were rapidly and reversibly eliminated by low $\left[\mathrm{Ca}^{2+}\right] /$ high $\left[\mathrm{Mg}^{2+}\right]$ bathing media, and substantially reduced by 0.5 or $1.0 \mathrm{mM}$ kynurenic acid. By contrast, d-tubocurarine (d-TC; up to 0.16 mM) reduced peak response amplitudes by less than $40 \%$, eliminated the third sink-source pair, and more than doubled the duration of decay of sink-source pairs 1 and 2 in a concentration-dependent manner. Strychnine had a similar action to d-TC but was slightly more potent. The time course and amplitudes of responses were not much affected by the following nicotinic agonists or antagonists (concentrations in $\mu \mathrm{M}$ ): mecamylamine, 50 ; dihydro- $\beta$-erythroidine, 50; nicotine, 200; tetramethylammonium, 500; $\mathrm{ACh}$ (protected by eserine, 20), 200; $\alpha$-bungarotoxin, $2 \mu \mathrm{M}$ for 2.5 $\mathrm{hr}$, and $0.4 \mu \mathrm{M}$ for up to $10.5 \mathrm{hr}$; and lophotoxin, $32 \mu \mathrm{M}$ for up to $94 \mathrm{~min}$. Eserine $(20 \mu \mathrm{M})$ and carbachol $(200 \mu \mathrm{M})$ increased peak response amplitudes by up to $80 \%$ within 5-10 min, and amplitudes remained elevated during 20-33 min of continued treatment. The onset of the effects of d-TC, strychnine, and kynurenic acid began in 5-10 min and was completed in $\mathbf{3 0}$ min or less, indicating that test substances could adequately penetrate into the interior of the isolated sections of tectum.

\footnotetext{
Received Apr. 10, 1986; revised Aug. 26, 1986; accepted Aug. 28, 1986.

We are grateful to Dr. P. B. Manis for his advice in the development of this assay system, and to him and Drs. J. J. Norden, J. T. Schmidt, and G. E. Kemp for thoughtful comments concerning the interpretation of these data. This work was supported by Grants EY01 117 and EY07007 from the National Eye Institute.

Correspondence should be addressed to Prof. John A. Freeman at the above address.

a Present address: Section of Neuroanatomy, Yale University School of Medicine, 333 Cedar Street, New Haven, CT 06510.

Copyright (C) 1987 Society for Neuroscience $0270-6474 / 87 / 030760-14 \$ 02.00 / 0$
}

The failure of these cholinergic ligands to prevent postsynaptic responses indicates that excitatory retinotectal transmission does not depend on an intact nicotinic (or other cholinergic) system, as previously proposed. The action by kynurenic acid suggests the involvement of an excitatory amino acid neurotransmitter in retinotectal transmission. The effects of d-TC and strychnine on the time course of responses are consistent with previous reports showing that these alkaloids can antagonize various amino acid-mediated inhibitory neurotransmission systems, and they suggest that members of this class of neurotransmitter play a role in an intrinsic tectal circuit which inhibits responses of tectal neurons to diffuse or repetitive retinofugal excitation.

The characterization of the $\mathrm{C} 10$ subtype of nicotinic acetylcholine receptor $(\mathrm{nAChR})$ has progressed to a high level of precision (reviewed by Changeux et al., 1984; Stevens, 1985). Considerable evidence exists to suggest that this protein (or a closely related protein) serves some important function in the vertebrate CNS (reviewed by Morley and Kemp, 1981; Oswald and Freeman, 1981; Freeman and Norden, 1984; Clarke et al., 1985). Much of this evidence is based on the specific and high-affinity binding of $\alpha$-bungarotoxin ( $\alpha$-BTX) to presumed nAChR. Attempts to correlate such binding with a role in interneuronal neurotransmission, however, have not been particularly successful (Brown, 1979). For example, $\alpha$-BTX has been demonstrated to bind to autonomic nAChR without blocking sensitivity to ACh (Brown and Fumigalli, 1977; Patrick and Stallcup, $1977 \mathrm{a}, \mathrm{b}$ ), and this ligand does not block collateral motoneuron output to Renshaw cells (Duggan et al., 1976), the best characterized central nicotinic system. To account for these findings, it has been proposed that interneuronal nAChRs are evolutionarily related to the neuromuscular $(\mathrm{C} 10) \mathrm{nAChR}$, having retained binding activity but having evolved into a form insensitive to the anticholinoceptive action of $\alpha$-BTX (Morley and Kemp, 1981; Oswald and Freeman, 1981; Conti-Tronconi et al., 1985).

This hypothesis has been supported by evidence obtained in relatively primitive vertebrates, specifically teleosts and amphibians, that fast excitatory retinotectal transmission is mediated by $\mathrm{nAChRs}$ that are antagonized by $\alpha$-BTX (Freeman, 1977; Schmidt and Freeman, 1980; Schmidt, 1985). Extracellular field potentials generated by electrical stimulation of the optic nerve or tract were dramatically reduced in vivo after subpial injection of $\mathrm{nAChR}$ antagonists in goldfish (Schmidt and Freeman, 1980; Schmidt, 1985) and after topical application of $\alpha$-BTX in toads (Freeman, 1977). Furthermore, there are several cholinergic markers in the optic neuropil of the tectum (reviewed 


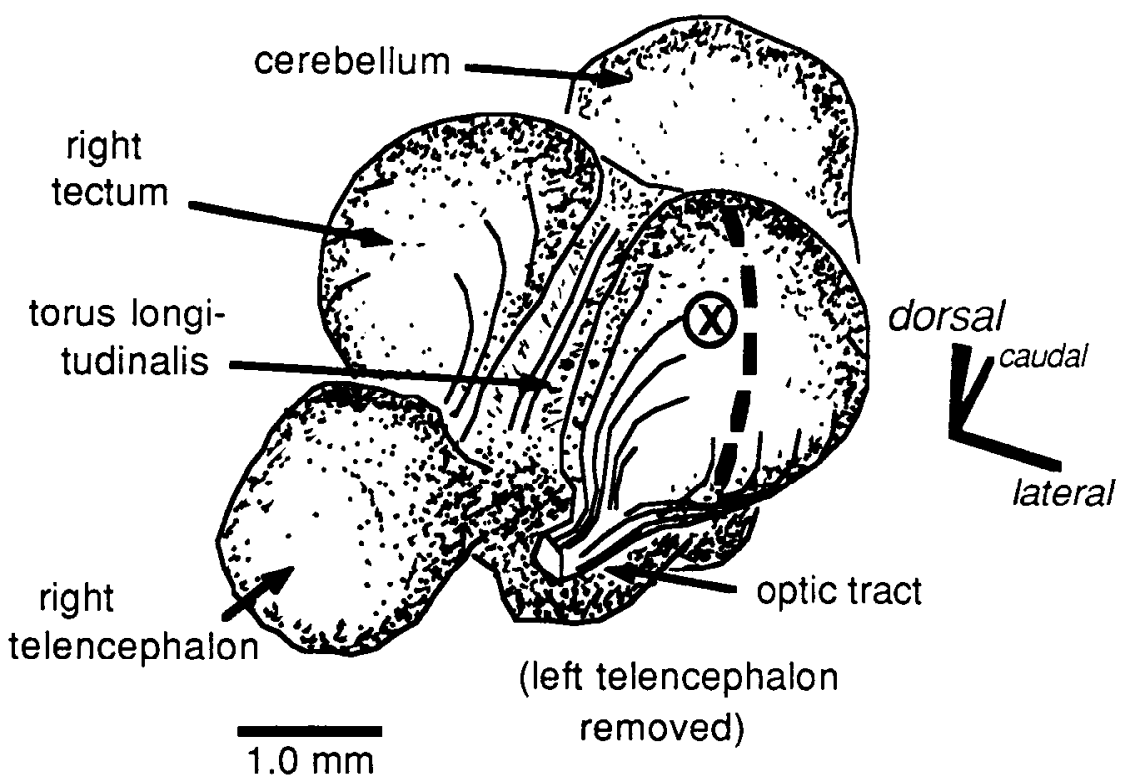

Figure 1. The goldfish brain and the site of field potential recordings (the circled $x$ ), rostrodorsolateral view. Struclures ventral and caudal to the cerebellum, the vagal lobe and rhombencephalon, have been omitted. The tectum is nearly spherical, so the length of the presynaptic fibers in this preparation is not accurately portrayed by this perspective; similarly, the relative size of the telencephalon appears somewhat exaggerated (cf. Meek, 1983). When preparing isolated tecta, the cerebellum and telencephalic lobes were aspirated and the optic tracts were sectioned between the chiasm (not shown) and the tecta prior to removal of the mesencephalon from the cranial cavity. Because a broad ventricle underlies the 2 tori longitudinalis and hemi-tecta, these could be isolated from the rest of the mesencephalon by cutting around the lateral margins (after midsagittal sectioning). Each hemi-tectum was then bisected (as indicated by the heavy dotted line), and recordings were made within $300 \mu \mathrm{m}$ of this cut margin. by Freeman and Norden, 1984), including a macromolecule that binds $\alpha$-BTX and resembles the C10 nAChR biochemically (Oswald and Freeman, 1979, 1981) and immunologically (Sargent et al., 1984; Henley et al., 1986a). Additional evidence has come from intracellular recordings in tectal slices (Freeman and Norden, 1984). Finally, this hypothesis has taken on significance concerning proposed activity-dependent synaptic self-organization, because $\alpha$-BTX has been shown to destabilize retinotopic order in toads (Freeman, 1977) and goldfish (Schmidt, 1985). Moreover, this destabilization does not occur when optic fiber impulses are blocked by intraocular injections of TTX (Schmidt, 1985).

Not all of the previous evidence, however, has supported the hypothesis that tectal field potentials depend on intact AChR. For example, $d$-tubocurarine (d-TC, $1 \mathrm{~mm}$ or greater) prolonged and did not much diminish tectal field potentials when applied topically in frogs (Stevens, 1973) or by subpial injection in goldfish (Schmidt and Freeman, 1980), and Konishi (1960) reported inconsistent actions of $31 \mathrm{~mm}$ nicotine applied topically to goldfish. In these earlier studies, test substances were applied in high concentrations with the expectation that they would undergo considerable dilution before reaching their site of action. No correlation could be made, therefore, between specific ligand concentrations and drug effects. In the present study, to allow more precise and uniform treatments with test substances, slices of tectum were maintained in vitro (Teyler et al., 1981), and pharmacologic agents were administered to the media bathing the slices. The test substances included drugs that affect cholinergic transmission, and also strychnine and kynurenic acid. The goals were (1) to obtain more conclusive evidence for the hypothesis that retinotectal transmission is mediated by the $\mathrm{nAChR}$; (2) to characterize the subtype of $\mathrm{AChR}$ involved on the basis of antagonist potencies (Paton and Zaimis, 1949; reviewed by Brown, 1979); and (3) to test for a CNS action by the novel nicotinic probe lophotoxin, which has been shown to antagonize both $\mathrm{C} 6$ and $\mathrm{C} 10$ nicotinic transmission irreversibly (Langdon and Jacobs, 1983, 1985).

Contrary to our expectations, nicotinic ligands applied in vitro at concentrations known to block transmission in other nicotinic systems were ineffective in substantially reducing the amplitudes of field potentials elicited by stimulation of the optic tract. Several pronounced drug or cation actions were observed, however, verifying that substances introduced via the bath could readily penetrate the tectal sections. Low $\left[\mathrm{Ca}^{2+}\right] /\left[\mathrm{Mg}^{2+}\right]$ media or kynurenic acid rapidly and reversibly decremented evoked field potentials, and response durations were considerably increased by $\mathrm{d}-\mathrm{TC}$ and strychnine. The results indicate that $\mathrm{nAChRs}$ are unlikely to play a primary role in excitatory retinotectal transmission, although they may modulate retinotectal transmission via a calcium-dependent process (P. B. Manis and J. A. Freeman, unpublished observations) occurring in retinal terminals, where they appear to be concentrated (Henley et al., 1986b; and P. B. Sargent, personal communication). Our results also indicate that inhibitory amino acid neurotransmitters may play a role in limiting the duration of tectal responses to excitatory retinofugal input. The block produced by kynurenic acid provides preliminary data implying that retinotectal transmission is glutaminergic (Perkins and Stone, 1982; Jahr and Jessell, 1985; Jahr and Yoshioka, 1986), a hypothesis for which we provide additional data elsewhere (Langdon and Freeman, 1986). We propose that differences between the present results and previous results obtained using micropressure injection of test substances may be due to the removal, when using the present in vitro procedure, of modulatory inputs to the tectum and/or subtle effects of increased tissue pressure engendered when substances were injected in vivo.

A preliminary account of some of this work has been reported (Langdon et al., 1985).

\section{Materials and Methods}

Goldfish (Carassius auratus, Common Comet variety, 4.5-6.0 gm; Grassyfork Fisheries, Martinsville, IN) were anesthetized by immersion in ice water for $5 \mathrm{~min}$. The mesencephalon and optic tracts were removed and transferred to ice-cold oxygenated medium before further dissection. This same medium was used during experiments, except as modified by drug additions or $\left[\mathrm{Ca}^{2+}\right]$ and $\left[\mathrm{Mg}^{2+}\right]$ changes. It was composed of (in $\mathrm{mm}$ ): $\mathrm{NaCl}, 120 ; \mathrm{KCl}, 2.5 ; \mathrm{CaCl}_{2}, 2.5 ; \mathrm{MgSO}_{4}, 1.2$; 
Figure 2. Profiles of normal (a) field potentials, $(b)$ current source densities (CSDs) derived from their second spatial derivatives, and $(c)$ the effect of a low $\left[\mathrm{Ca}^{2+}\right] /$ high $\left[\mathrm{Mg}^{2+}\right]$ medium on the same. The field potential traces begin with system gain and impedance test pulses, followed by the stimulation artifacts. The CSD traces begin at the end of these artifacts. The broad arrow at $150 \mu \mathrm{m}$ depth in $(a)$ indicates the largest presynaptic wave. Circled numbers identify 3 postsynaptic waves. In $c$, there is a remaining sink-source pair with a peak density of $10.3 \mathrm{~mA} / \mathrm{cm}^{3}$. This was absent in $\mathrm{Ca}^{2+}$ concentrations of $0.4 \mathrm{~mm}$ or lower (not shown).

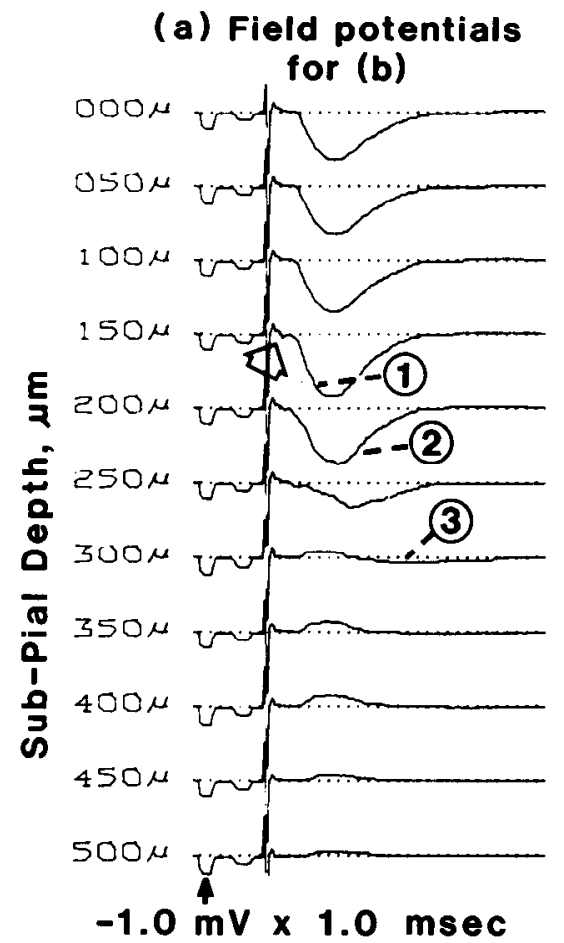

Radial Current Source Densities

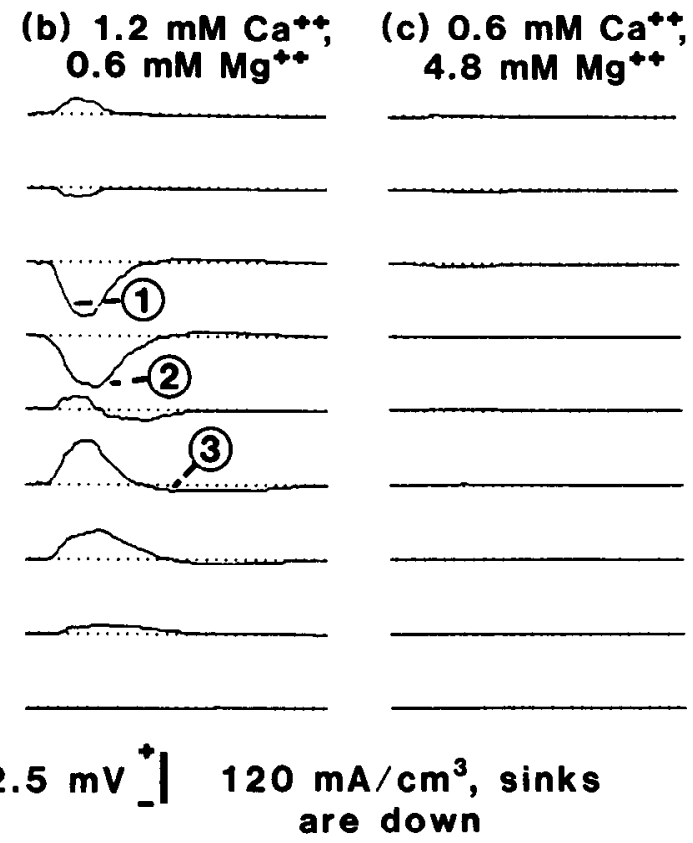

$d$-glucose, 10; phenol red, 0.01; HEPES, $10 ; \mathrm{Na}_{2} \mathrm{HPO}_{4}, 1.0$; $\mathrm{NaOH}$, 1.5 (to bring to $\mathrm{pH} 7.35$ ). The experimental preparations included the rostromedial half of the hemitectum, a short section of the lateral branch of the optic tract, the entire medial branch with most of its projection, and the torus longitudinalis (Fig. 1). These sections were transferred to a $0.3 \mathrm{ml}$ Plexiglas chamber lined with Sylgard and held in place with $0.1 \mathrm{~mm}$ diameter wire pins. Sections were either pinned with the pial surface against the Sylgard ("pial-side-down") or with the ventricular surface so oriented ("pial-side-up"). The amplitudes of field potentials differed between these 2 arrangements, but current source density profiles did not (see Results). Since the sections were not precisely planar, in neither case was much of the surface abutted against the lining. Either arrangement appeared to afford excellent viability and rapid equilibration after changes in the bath composition.

A jet of humidified oxygen was directed obliquely into the bath (Koerner and Cotman, 1983). All recordings were made at temperatures between 18 and $21^{\circ} \mathrm{C}$. In earlier experiments, the fluid in the bath $(0.3$ $\mathrm{ml}$ ) was exchanged by at least 2 vol every $15 \mathrm{~min}$. Later experiments used continuous $(\sim 0.05-0.1 \mathrm{ml} / \mathrm{min})$ superfusion. Rapid exchange (1 $\mathrm{ml} / \mathrm{min}$ ) with at least 5 bath volumes was used in switching to media of new composition. During the recording of depth profiles, superfusion was routinely interrupted for $5-10 \mathrm{~min}$ without discernible adverse effect.

To provide for well-localized stimulation, the stump of the optic tract was aspirated into a snugly fitting glass pipette. Maximal responses were elicited by delivery of $6-17 \mathrm{~V}$ for $0.2-0.6 \mathrm{msec}$, with the cathodal pole in the tissue bath and the anodal pole in the pipette lumen. Stimuli were delivered at $0.25 \mathrm{~Hz}$ continuously throughout the duration that each preparation was maintained (typically $5-10 \mathrm{hr}$ ). Field potential profiles were generally recorded from the central region of the tectum, with 300 $\mu \mathrm{m}$ of the transected margin (Fig. 1). Field potentials were recorded with glass micropipette electrodes pulled from 1.0-mm-diameter capillarics fillcd with $4 \mathrm{M} \mathrm{NaCl}$ and broken back to resistances between 2 and $5 \mathrm{M} \Omega$. Responses to 5 or more stimuli were collected at each sample depth (separated by $50 \mu \mathrm{m}$ ), and averaged on a PDP-12 computer. Peak response amplitudes were estimated from recordings digitized at $4 \mathrm{kHz}$ or faster. Sampling at lower rates was also used at times to allow complete recording of responses prolonged by drug treatments. Three prominent $\mathrm{Ca}^{2+}$-dependent responses were observed and numbered in chronological order (Fig. 2), similar to the nomenclature of Konishi (1960) and Schmidt (1979). Depth profiles of current sinks and sources (CSD profiles) were calculated as previously described (Freeman and Nicholson, 1975: smoothing formula "D3"). Smoothed second derivatives (in
$\mathrm{mV} / \mathrm{cm}^{2}$ ) were converted to CSDs (in $\mathrm{mA} / \mathrm{cm}^{3}$ ) by assuming that the conductivity in the radial dimension was uniformly $250 \Omega-\mathrm{cm}$, as was previously observed in a different teleost (Eugerres) by Vanegas et al. (1979). The reference position for depth beneath the pial surface was cstablished by noting the incrcased clcetrical noisc as the recording tip passed across the pial surface. Detection of these points was facilitated by passing the electrode potential through a voltage-controlled oscillator and audio monitor circuit (Langdon and Jacobs, 1980). Response durations were quantified by determining "half-widths" (Rall, 1967).

All of the pharmacological agents were applied at concentrations in excess of those previously reported to specifically antagonize neurotransmission in other synaptic systems, as well as in lower concentrations. Antagonist activity of each stock of cholinergic ligand employed was verified by assaying neurotransmission at these same concentrations in the isolated frog sartorius and frog lumbar sympathetic ganglion preparations, using procedures described previously (Langdon and Jacobs, 1983, 1985). Electrolytes were purchased from Mallincrodt Chem. (St. Louis, MO) and were of reagent grade. Drugs were purchased from Sigma Chem. Co. (St. Louis, MO), with the exceptions of mecamylamine and dihydro- $\beta$-erythroidine, which were donated by Merck and Co., Inc. (West Point, PA), and lophotoxin, which was supplied by Dr. Paul Culver of the University of California at San Diego. Lophotoxin was solubilized by dissolving in dimethylsulfoxide $(10 \mathrm{mg} / \mathrm{ml})$. The molarities of $\alpha$-BTX solutions were calculated assuming a molecular weight of $9 \mathrm{kDa}$.

\section{Results}

\section{Control responses}

Normal response profiles were typically comprised of several small, rapid, $\mathrm{Ca}^{2+}$-independent (nonsynaptic) waves followed by 3 much larger and relatively slow waves (Fig. 2a), closely resembling in both amplitude and time course those previously described in detail both in vivo (reviewed by Vanegas, 1983) and in vitro (Matsumoto and Bando, 1981; Teyler et al., 1981). Where they were their largest, in the superficial optic neuropil, the nonsynaptic waves were less than $0.6 \mathrm{mV}$ in amplitude, and therefore barely evident on plots at a scale appropriate for display of the entire response profiles. However, the largest of these waves is clearly visible in Figure 11. The latencies of these waves 
(1-4 msec) were in reasonable agreement with the previously reported conduction velocities of optic tract fibers.

Waves 1 and 2 have been labeled as separate in Figure 2, even though they were almost completely overlapping. Their temporal separation was greater in prior in vivo studies and has been attributed to the existence of different conduction velocity groups in the optic tract fibers (Schmidt, 1979; Vanegas, 1983). Greater overlap was therefore expected in this present study because there was a length of only about $5 \mathrm{~mm}$ of optic tract present. Because of the amount of overlap, waves 1 and 2 were treated as 1 response when quantifying peak amplitudes and durations, and the negative field potential wave comprised of these 2 components in the superficial optic neuropil will be referred to as the $\mathrm{N}$-wave. Precise quantification of response 3 was impractical because it was superimposed to an uncertain degree upon the tails of responses 1 and 2 .

In pial-side-down sections, $\mathrm{N}$-waves (between 100 and 200 $\mu \mathrm{m}$ depth) were larger than their positive inversions at greater depth (Fig. $2 a$ ). In pial-side-up sections, the converse was true, with the average $\mathrm{N}$-wave peak amplitudes differing between the 2 arrangements by roughly 2 -fold (not shown). These differences were attributable to the asymmetry of the recording environment; the bottom of the tissue section closely faced the bottom of the chamber, which was not elcctrically conductive, whereas the upward surface was covered by 2 to $3 \mathrm{~mm}$ of (conductive) saline. Most of the data presented were collected from pial-sideup preparations, for which the initial mean $\mathrm{N}$-wave amplitude in 25 preparations was $-2.09 \mathrm{mV}$ (range, -1.1 to $-3.4,1 \mathrm{SD}=$ $0.77 \mathrm{mV}$ ). In 13 pial-side-down preparations, the mean amplitude before treatment was $-3.89 \mathrm{mV}$ (range, -2.81 to $-5.4,1$ $\mathrm{SD}=0.71$ ). Profiles of CSDs estimated from the field potentials collected with either arrangement did not differ appreciably, as illustrated by comparison of the pretreatment profiles in Figures $4 a, 6, b$ and $c$, and $8 b$ (pial-side-up) with Figures $6 a, 7,8, a$ and $c$, and $9 a$ (pial-side-down). CSD profiles typically exhibited maximal CSDs between 75 and $150 \mathrm{~mA} / \mathrm{cm}^{3}$. The total of sources and sinks, summed vertically across the tectum within individual response profiles, was always nearly zero. This was consistent with an earlier 3-dimensional CSD analysis in vivo (Freeman et al., 1980), from which it was concluded that the currents evoked by supramaximal stimulation of the optic tract are predominantly radial in orientation.

Response profiles remained much the same during the first 5-10 hr after dissection. After that, predictable changes took place in time course and, to a lesser degree, amplitude. These have been described (R. B. Langdon, P. B. Manis, and J. A. Freeman, unpublished observations) and summarized in a scction below that concerns the reversibility of drug effects. All of the measurements of drug effects were made with preparations less than $11 \mathrm{hr}$ old.

Occasionally, in vitro sections underwent temporary episodes of inexcitability that resembled spreading depression (e.g., Snow et al., 1983). Typically, these began with an abrupt baseline shift and complete flattening of field potentials. Some responsiveness returned in 2-5 $\mathrm{min}$, and normal profiles were restored within $20 \mathrm{~min}$. These episodes occurred in $18 \%$ of 17 preparations maintained under continuous perfusion, and in $71 \%$ of 14 preparations maintained by periodic bath exchanges. The episodes often began spontaneously but sometimes coincided with mechanical trauma to the preparation. They did not occur repeatedly and therefore did not interfere much with experimentation. In evaluating drug effects on response amplitudes, measure-
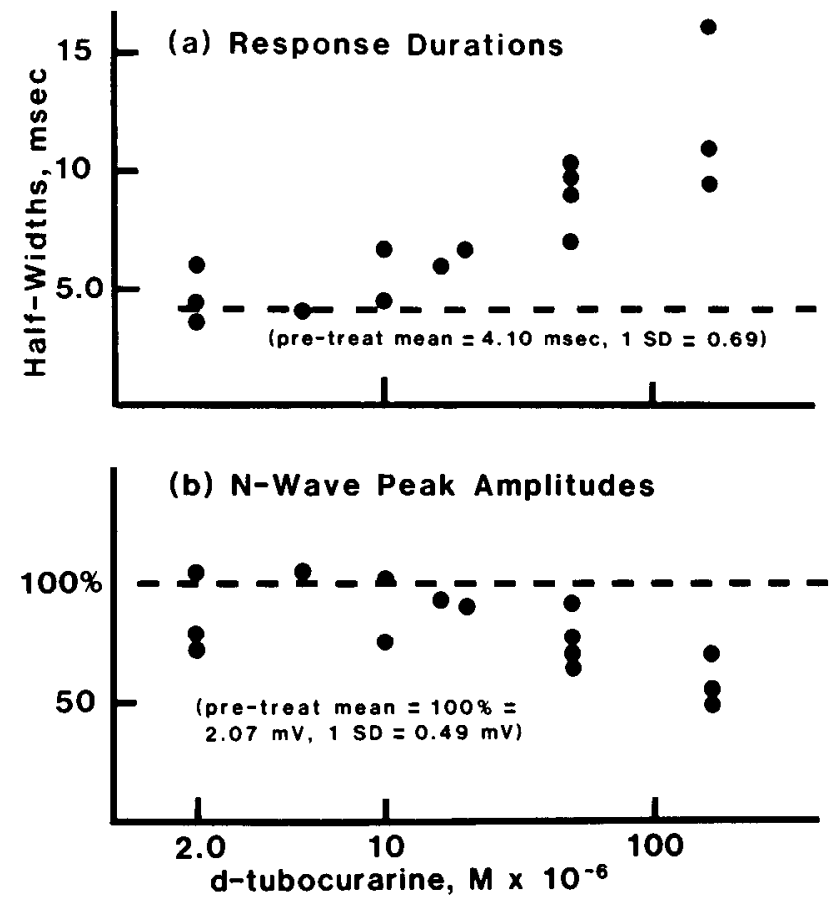

Figure 3. Log concentration-effect curves for d-TC action on the (a) durations and $(b)$ amplitudes of $\mathrm{N}$-waves; combined data from 11 experiments.

ments were postponed, if necessary, until after recovery from episodes of apparent spreading depression.

A very late and slow superficial sink to deep source that resembled the "long-latency response" described by Teyler et al. (1981) was often observed if stimulation was preceded by 10 or more sec without stimulation. It was usually absent when stimulating at $0.25 \mathrm{~Hz}$ but can be seen in one of the CSD profiles presented (Fig. 6c).

\section{Responses in high $\left[\mathrm{Mg}^{2+}\right]$ and/or low $\left[\mathrm{Ca}^{2+}\right]$}

Initially, many experiments were begun by bathing preparations in high $\left[\mathrm{Mg}^{2+}\right]$ and/or low $\left[\mathrm{Ca}^{2+}\right]$ media, which reduce or completely prevent evoked release of neurotransmitters (Katz, 1969; Hubbard, 1973; Krnjević, 1974; Dingledine and Somjen, 1981). Teyler et al. have reported (1981) that field potentials in whole isolated tecta are rather resistant to such bath changes. In the present work (in which tecta were sectioned), rapid response to low $\left[\mathrm{Ca}^{2+}\right] /\left[\mathrm{Mg}^{2+}\right]$ media provided assurance that the extracellular fluid around the recording site was in reasonably rapid equilibrium with the bath, at least as regarded small ions in solution. Only the very small and rapid "nonsynaptic" waves mentioned above were insensitive to such bath media. When the $\left[\mathrm{Ca}^{2+}\right]$ was below $0.4 \mathrm{~mm}$, all 3 slow response waves were eliminated, and this block was virtually complete in $4.8 \mathrm{~mm}$ $\mathrm{Mg}^{2+}, 0.6 \mathrm{mM} \mathrm{Ca}{ }^{2+}$ (Fig. 2c). In distinction to the occasional spontaneous episodes of apparent spreading depression, the onset of this action was gradual and the effect continued throughout the duration of the treatment. This was also true for all other reductions in response amplitudes described below. The initial effects of changes in $\left[\mathrm{Mg}^{2+}\right]$ and $\left[\mathrm{Ca}^{2+}\right]$ appeared in $1-5 \mathrm{~min}$, and equilibrations to new levels were completed in 15-30 min (not shown; see also Langdon et al., 1985). 
Figure 4. Effect of $160 \mu \mathrm{M}$ d-TC on current sources and sinks. All 4 profiles were derived from field potentials recorded from the same electrode penetration. Regarding the time of profile (a) as zero, d-TC treatment began at 30 min and ended at $115 \mathrm{~min}$; profiles were sampled at $(b) 80,(c) 65$, and $(d) 175$ min. Profile $a$ was recorded $2.5 \mathrm{hr}$ after dissection. Each CSD trace in this and all of the other figures begins at the end of the stimulation period. Note time base differences.

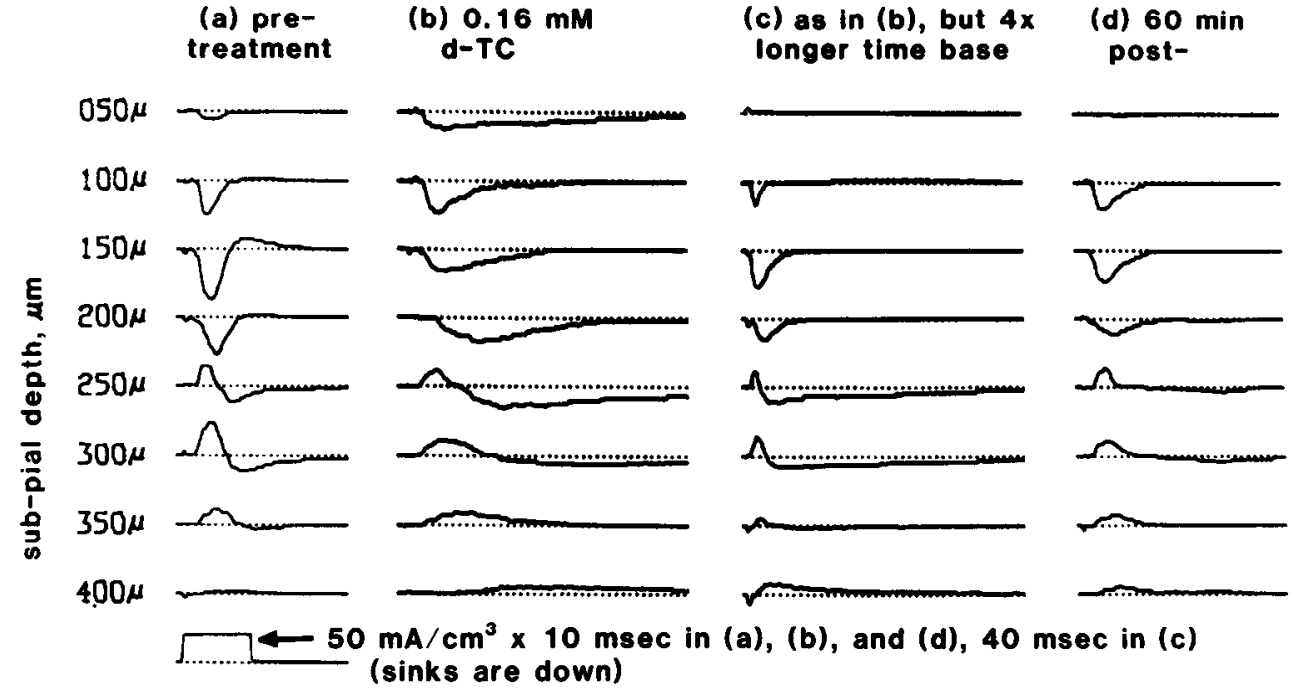

panied by a deeper source in the periventricular region (at 400 $\mu \mathrm{m}$ in Fig. 4), where normally littlc or no such activity was present. There also appeared a very low-amplitude, very late, and long superficial source (at $100 \mu \mathrm{m}$ in Fig. $4 c$ ). Overall, the d-TC action at 50 or $160 \mu \mathrm{M}$ was very similar to that observed in situ by Schmidt and Freeman (1980) after injection of 1-2 $\mu 11.0 \mathrm{~mm}$ (but not $0.1 \mathrm{~mm}$ ) d-TC into goldfish tectum.

In untreated tecta, successive responses were generally identical. However, during the first $10-20$ min of treatment with high levels of d-TC, responses were typically erratic. Successive responses sometimes differed in amplitude by as much as 3-fold with occasional responses exceeding those prior to treatment, and small background biphasic inflections occurred sporadically. (Because of averaging, these small transients are not apparent in the traces shown.)

The latencies of the peaks of $\mathrm{N}$-waves (and their correspond- and $350 \mu \mathrm{m}$, was prolonged to last for $0.1-0.5 \mathrm{sec}$ (Fig. $4 c$ ). The first portion of this deep, prolonged sink activity was accom-

Table 1. Effects of various treatments on the time course and amplitudes of field potentials evoked by optic tract stimulation

\begin{tabular}{lllllr} 
& $\begin{array}{l}\text { Sam- } \\
\text { ple } \\
\text { size }\end{array}$ & $\begin{array}{l}\text { Mean peak } \\
\text { amplitude } \\
\text { (\% pre- } \\
\text { treatment) }\end{array}$ & $\begin{array}{l}\text { Mean half- } \\
\text { duration } \\
\text { (\% pre- } \\
\text { treatment) }\end{array}$ & $\begin{array}{l}\text { Change in } \\
\text { peak latency } \\
\text { (msec) }\end{array}$ & \multicolumn{1}{c}{$\begin{array}{l}\text { Change in } \\
\text { rise latency } \\
\text { (msec) }\end{array}$} \\
\hline (a) dreatment & 4 & $79(10)$ & $207(26)$ & $+0.8(1.1)$ & $+0.1(0.2)$ \\
(b) d-TC & 3 & $59(16)$ & $294(96)$ & $+2.8(1.9)$ & $-0.1(0.1)$ \\
(c) Mccamylaminc & 3 & $90(4)$ & $95(20)$ & $+0.5(0.5)$ & $+0.1(0.2)$ \\
(d) Dihydro- $\beta$-erythroidine & 2 & $104(9)$ & $100(0)$ & $+0.6(0.6)$ & $+0.4(0.3)$ \\
(e) $\alpha$-BTX & 3 & $87(13)$ & $101(7)$ & $+0.7(0.3)$ & $+0.8(0.1)$ \\
(f) Lophotoxin & 2 & $82(23)$ & $101(17)$ & $-0.3(0.0)$ & $-0.2(0.6)$ \\
(g) Nicotine & 4 & $98(7)$ & $107(9)$ & $-0.1(0.1)$ & $+0.1(0.1)$ \\
(h) TMA & 2 & $108(14)$ & $108(20)$ & $+0.7(0.0)$ & $0.0(0.3)$ \\
(i) Eserine & 3 & $122(8)$ & $108(12)$ & $0.0(0.4)$ & $+0.1(0.1)$ \\
(j) ACh & 3 & $104(18)$ & $112(11)$ & $+0.0(0.5)$ & $0.0(0.2)$ \\
(k) Carbachol & 3 & $133(5)$ & $97(12)$ & $0.0(0.9)$ & $-0.1(0.3)$ \\
(l) Strychnine & 3 & $83(25)$ & $238(60)$ & $+1.4(1.0)$ & $+0.3(0.4)$ \\
(m) Kynurenic acid & 4 & $16(3)$ & $113(5)$ & $-0.2(0.3)$ & $0.0(0.1)$
\end{tabular}

Amplitudes and durations of field potentials during various pharmacological treatments, relative to pretreatment values. The specific treatments were as follows: (a) $50 \mu \mathrm{M}$ for $25-44 \mathrm{~min}$; (b) $160 \mu \mathrm{M}$ for 50-65 min; (c) $50 \mu \mathrm{M}$ for 35-40 min; (d) $50 \mu \mathrm{M}$ for 22-24 min; (e) 0.10-0.33 $\mu \mathrm{M}$ for 71-290 min; (f) $32 \mu \mathrm{M}$ for 15-94 min, sampled after 40-94 min; (g) 0.10$0.20 \mathrm{mM}$ for 18-45 min; (h) $0.50 \mathrm{mM}$ for 30-36 min; (i) $20 \mu \mathrm{M}$ for 17-26 min; (j) $0.20 \mathrm{mM}$ for $19-34 \mathrm{~min}$, with $20 \mu \mathrm{M}$ eserine and after 30-35 min of pretreatment with eserine; (k) $0.20 \mathrm{~mm}$ for 20-35 min; (l) $20-33 \mu \mathrm{M}$ for 22-41 min; (m) 0.50-1.0 $\mathrm{mm}$ for 14-21 min. Respective sample standard deviations are indicated in parentheses. 

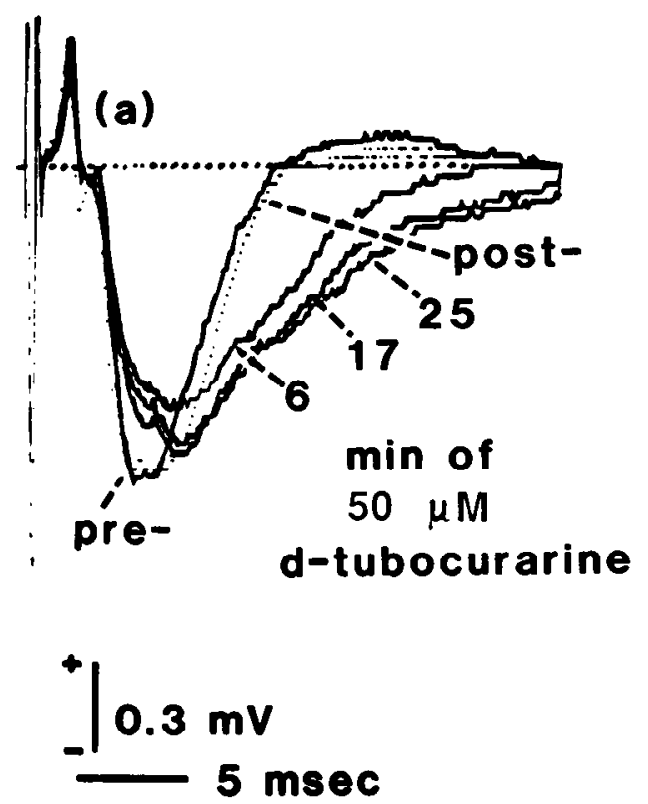

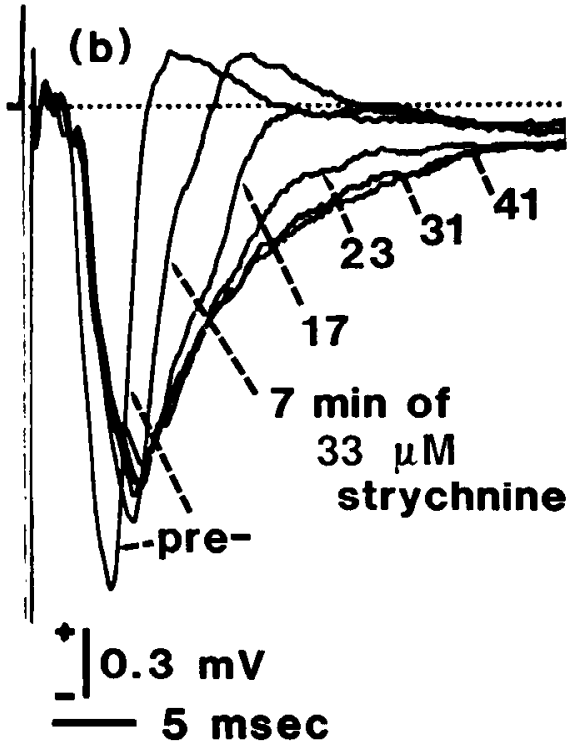

Figure 5. Typical time course of onset of actions of $(a)$ d-TC and $(b)$ strychnine. The traces are $\mathrm{N}$-waves $(150-200$ $\mu \mathrm{m}$ depth, sections oriented pial-sideup) recorded without intervening repositioning of the electrode. ing sinks) increased by $1-2 \mathrm{msec}$ in 50 or $160 \mu \mathrm{M}$ d-TC (Table 1; Figs. 4, 5, and 11). Often, a distinct notch appeared prior to the peak of negativity and sink density, and smaller notches or inflections appeared after the peak (Fig. 11). The latency of the peak of the late, deep sink increased by as much as $20 \mathrm{msec}$. This was due in part, however, to the lengthening of sink-source pairs 1 and 2, the tails of which are sources between 250 and $350 \mu \mathrm{m}$ and are superimposed upon and therefore partially cancel the initial portion of this deep sink activity. No treatment, neither with d-TC nor with any of the other agents used, altered the latency of the nonsynaptic waves or the beginning of responses.

The time course of onset for each active substance was closely examined as an indicator of the ability of bath-applied agents to penetrate the tectal sections. Equilibration after d-TC introduction was typically half-completed in 5-10 min, with little or no further increases in action after 20-30 min (Fig. 5a).

\section{Mecamylamine, dihydro- $\beta$-erythroidine, $\alpha$-bungarotoxin, and lophotoxin}

Mecamylamine is a low-molecular-weight $(0.167 \mathrm{kDa})$ and relatively lipophilic antagonist of nicotinic transmission in autonomic ganglia that is effective at submicromolar concentrations (Ascher et al., 1979). Dihydro- $\beta$-erythroidine is structurally related to d-TC but less bulky $(0.275 \mathrm{kDa})$. It blocks neuromuscular transmission and transmission between ventral horn motor neuron collaterals and Renshaw cells when bath-applied at $1.0 \mu \mathrm{M}$ (Jahr and Yoshioka, 1986). The snake venom component $\alpha$-BTX is a peptide of roughly $9 \mathrm{kDa}$ which, at $0.1 \mu \mathrm{M}$, produces a profound block of neuromuscular $\mathrm{nAChRs}$ in 10-15 min (Miledi and Potter, 1971). Lophotoxin is an uncharged, relatively low-molecular-weight $(0.416 \mathrm{kDa})$, and very lipophilic nicotinic antagonist that produces, at $32 \mu \mathrm{M}$, an irreversible block of either neuromuscular or sympathetic ganglion nicotinic transmission in 30-45 min (Langdon and Jacobs, 1983, 1985). After treatments with each of these substances in concentrations that have produced block in other nicotinic systems, mean peak response amplitudes remained between 81 and 104\% of their initial values, and response time courses were essentially unchanged (Figs. $6,7 a$; Table 1). Four experiments were run with $\alpha$-BTX using 2 different stocks of toxin, both of which were also assayed at $0.1 \mu \mathrm{M}$ in the isolated frog sartorius neuromuscular preparation, and which produced $>90 \%$ reduction in muscle contractions or end plate potentials in 27 to $30 \mathrm{~min}$ (not shown). In addition to the results averaged for the table entry, 1 preparation was treated with $2 \mu \mathrm{M} \alpha$-BTX for $2.5 \mathrm{hr}$, after which the response amplitude was $86.6 \%$ of its previous level. One treatment with $0.4 \mu \mathrm{M}$ was extended to $10.5 \mathrm{hr}$, after which the mean amplitude was still $79.4 \%$ of the initial value.

Two preparations were treated with the vehicle for lophotoxin, $0.2 \%$ DMSO, by itself for $1 \mathrm{hr}$, with no apparent effect.

\section{Nicotine, carbamylcholine (carbachol), and tetramethylammonium}

These 3 low-molecular-weight cholinergic ligands are effective agonists for either neuromuscular or autonomic $\mathrm{nAChR}$ at concentrations between 5 and $100 \mu \mathrm{M}$ (Thesleff, 1955; Ginsborg and Guerrero, 1964; Payton, 1966). They block nicotinic transmission first by producing postsynaptic depolarization and then by receptor desensitization (Paton and Perry, 1953; Thesleff, 1955). Carbachol is also an effective muscarinic agonist at these concentrations (Bolton, 1972).

Tectal responses were unaffected by $0.1-0.2 \mathrm{~mm}$ nicotine for as long as $45 \mathrm{~min}$ (Fig. 8a). In contrast, the peak amplitudes of field potentials increased to between 140 to $180 \%$ of the pretreatment values during the first $5 \mathrm{~min}$ of carbachol treatments $(0.20 \mathrm{~mm}, 3$ experiments). This response enhancement declined gradually thereafter, but mean amplitudes remained at $133 \%$ of pretreatment levels after 20-35 min (Table 1). At this same time, the mean peak sink density was elevated to $127 \%$ (1 SD = $13.9 \%$; Fig. $8 b)$. Tetramethylammonium $(0.50 \mathrm{~mm}, 2$ experiments) appeared to enhance responses slightly, again with the largest effect occurring about 5 min after beginning treatment (Fig. 8c). 


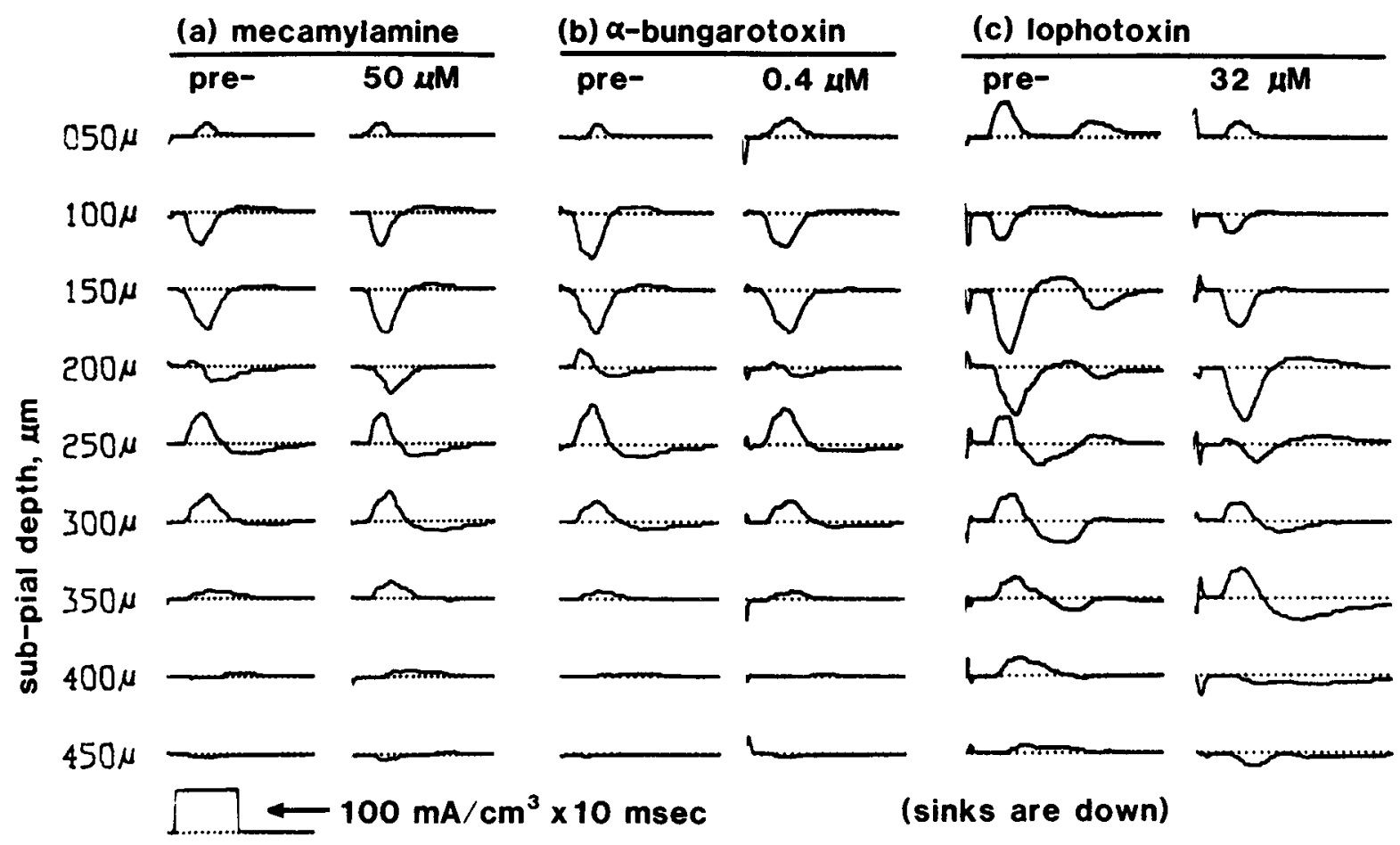

Figure 6. Examples of CSD profiles sampled before and during treatments with (a) mecamylamine, $50 \mu \mathrm{M}$ for $37 \mathrm{~min}$; (b) $\alpha$-BTX, $0.4 \mu \mathrm{M}$ for 5 hr; and (c) lophotoxin, $32 \mu \mathrm{M}$ for $94 \mathrm{~min}$. The pretreatment profile of $c$ was recorded after $60 \mathrm{~min}$ of $0.2 \% \mathrm{DMSO}$, the vehicle used to dissolve lophotoxin.

\section{ACh and eserine}

ACh blocks nicotinic transmission by depolarization and desensitization when applied at 25-100 $\mu \mathrm{M}$ (Thesleff, 1955) but is vulnerable to hydrolysis by endogenous AChE. This agonist was therefore protected from hydrolysis by including $20 \mu \mathrm{M}$ eserine in the tissue bath prior to and during $\mathrm{ACh}$ treatments (Thesleff, 1955; Cole and Nicoll, 1984). The pretreatment with eserine alone appreciably enhanced response amplitudes (Fig. 9a). The peak enhancement occurred 7-12 min after beginning treatment, with the mean peak amplitude rising to $125 \%$ (1 SD = 11.4). This effect faded gradually thereafter. The subsequent addition of $0.20 \mathrm{~mm} \mathrm{ACh}$ to the bath did not appear to alter this gradual decline to the pretreatment response levels (Table 1).

\section{Strychnine}

Strychnine is a relatively bulky alkaloid (molecular weight $=$ $0.767 \mathrm{kDa}$ ) that antagonizes inhibitory neurotransmission mediated by neutral amino acids (Curtis and Crawford, 1969). It is generally thought of as a glycine antagonist but has also been observed to antagonize responses to GABA at concentrations between 10 and $100 \mu \mathrm{M}$ (Scholfield, 1982). Its effects (4 experiments) were very similar to those of d-TC (cf. Figs. 4 and $7 b$ ), but strychnine was slightly more potent (cf. Figs. 3 and 10). Like d-TC, strychnine broadened responses greatly (to $273 \%$ ), caused them to become more erratic, and delayed the time of maximal response. Strychnine produced prolongation at $100 \mu \mathrm{M}$ comparable to d-TC action at $160 \mu \mathrm{M}$, and produced a modest (up to $40 \%$ ) concentration-dependent decrease in peak amplitude. The time course of onset of strychnine action was very similar to that for d-TC (Fig. $5 b$ ).

\section{Kynurenic acid}

Kynurenic acid is a relatively small $(0.189 \mathrm{kDa})$ and lipophilic antagonist of depolarization elicited by acidic amino acids such as glutamate and $N$-methyl-D-aspartic acid (Perkins and Stone, 1982; Ganong et al., 1983; Jackson et al., 1985; Jahr and Jessell, 1985). Assayed by intracellular recordings from dissociated dorsal horn neurons cocultured with dorsal root ganglia, $0.5 \mathrm{~mm}$ markedly reduced postsynaptic depolarizations. However, concentrations up to $1.0 \mathrm{~mm}$ did not interfere with recurrent inhibition of ventral horn motor neurons (Jahr and Yoshioka, 1986), which is widely regarded as depending upon nicotinic synapses onto Renshaw cells. In the present study ( 4 experiments) a profound block of tectal responses rapidly followed treatment with either 0.5 or $1.0 \mathrm{~mm}$ (Fig. $9 e$; Table 1). The level of block stabilized in 10-20 $\mathrm{min}$, and the return of responsivity after resumption of drug-free medium was similarly rapid.

\section{In vitro viability and the reversibility of drug actions}

Complete return to the pretreatment response pattern was observed after many, but not all, treatments with d-TC (Fig. 5a) and strychnine (not shown). The effect of time in vitro without drug treatment was examined to assure that loss of viability was not mistaken for any acute or irreversible drug action. Beginning 5-10 hr after dissection, response profiles showed changes resembling the reversible effects of low $\left[\mathrm{Ca}^{2+}\right] /$ high $\left[\mathrm{Mg}^{2+}\right]$ solutions, which will be reported in greater detail elsewhere (Langdon et al., unpublished observations). Principally, these consisted of (1) loss of up to roughly $40 \%$ of the peak amplitude of responses 1 and 2 ; (2) broadening of these responses with halfwidths asymptotically assuming values of 4-5 $\mathrm{msec}$; and (3) complete loss of response 3 . Figure $4 d$ presents an example of 
(a) dihydro- $\beta$-erythroldine

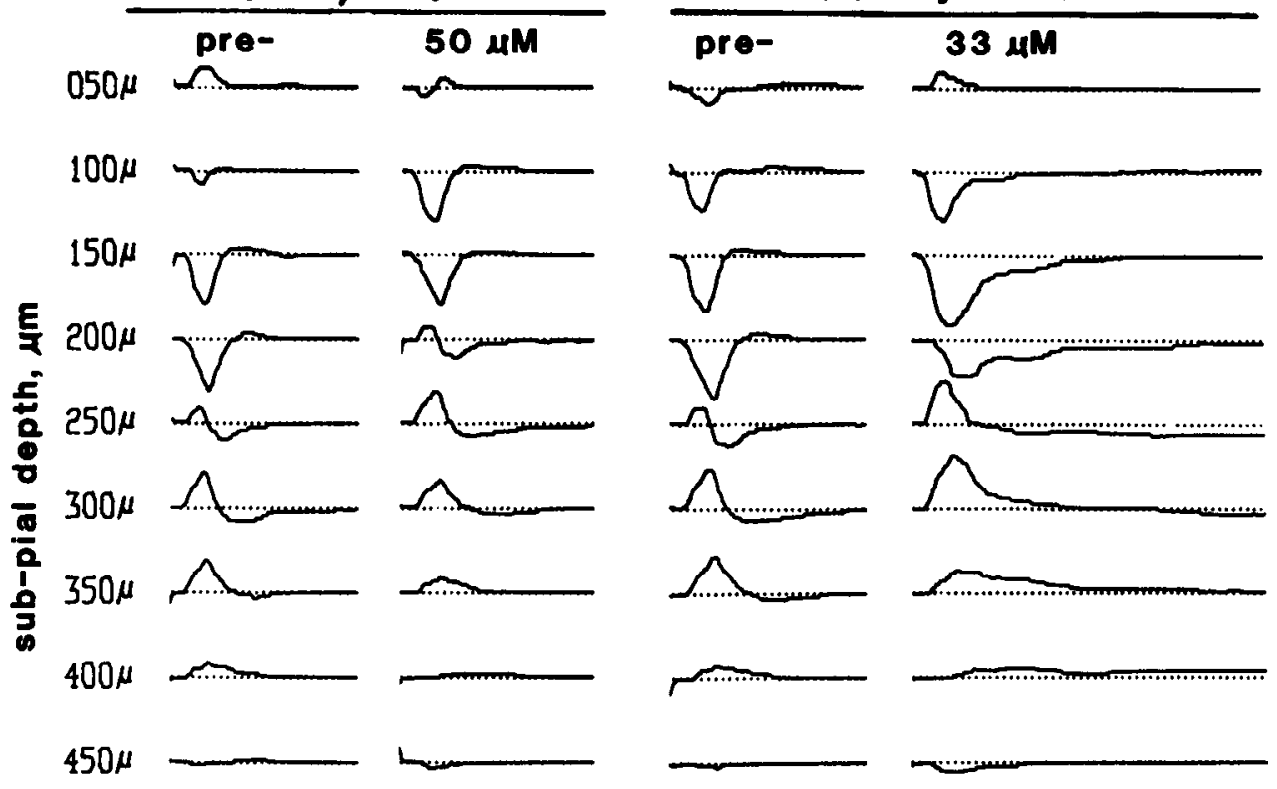

Figure 7. Examples of CSD profiles sampled before and during treatments with (a) dihydro- $\beta$-erythroidine, $50 \mu \mathrm{M}$, and $(b)$ strychnine, $33 \mu \mathrm{M}$. All 4 profiles were recorded from the same hemi-tectum and electrode placement. incomplete return of a d-TC-treated preparation to the initial state, in which the posttreatment profile resembles those observed in untreated preparations after $5-10 \mathrm{hr}$.

Low levels of d-TC and strychnine also produced effects (1) and (2) above, but these agents always enhanced and prolonged deep sink activity, in contrast to the effect of tissue deterioration. Furthermore, high levels of d-TC and strychnine prolonged responses 1 and 2 much more than did elapsed time in vitro or divalent ion manipulations. All of the data were consistent with the assertion by Vanegas et al. (1974; Vanegas, 1983) that the peak of the $\mathrm{N}$-wave is generated by a second-order population spike. Like these previous investigators, we also observed a distinct shoulder or "hump" in many normal N-waves (Fig. 11). Although the peak negativity and sink activity were delayed by d-TC, the time of this shoulder was not. After washout ( $3 \mathrm{hr}$ after the pretreatment traces in Fig. 11), the $\mathrm{N}$-waves sometimes

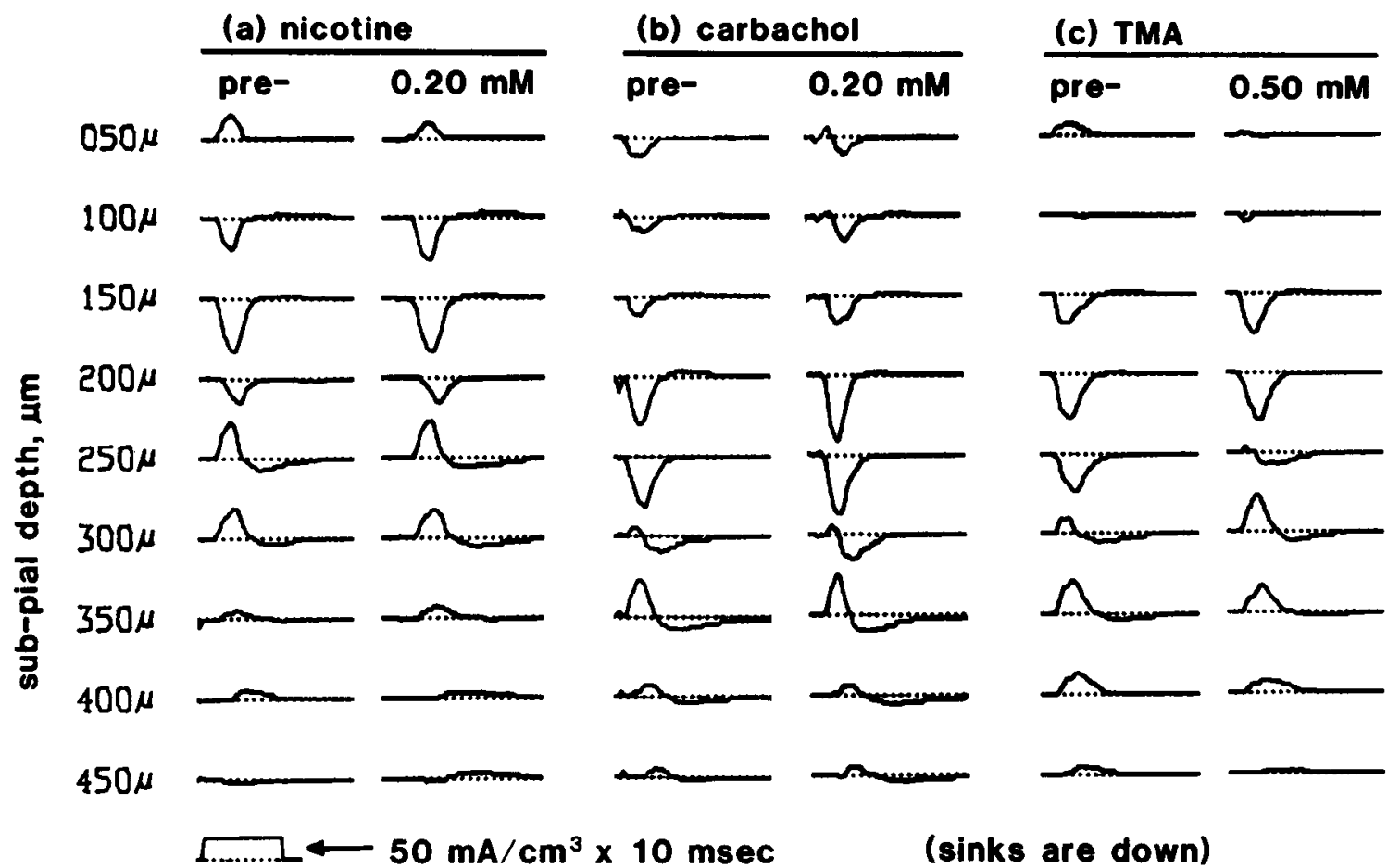

Figure 8. Examples of CSD profiles sampled before and during treatments with (a) $0.20 \mathrm{~mm}$ nicotine for $45 \mathrm{~min},(b) 0.20 \mathrm{mM}$ carbachol for 30 $\mathrm{min}$, and $(c) 0.50$ TMA for $30 \mathrm{~min}$. 


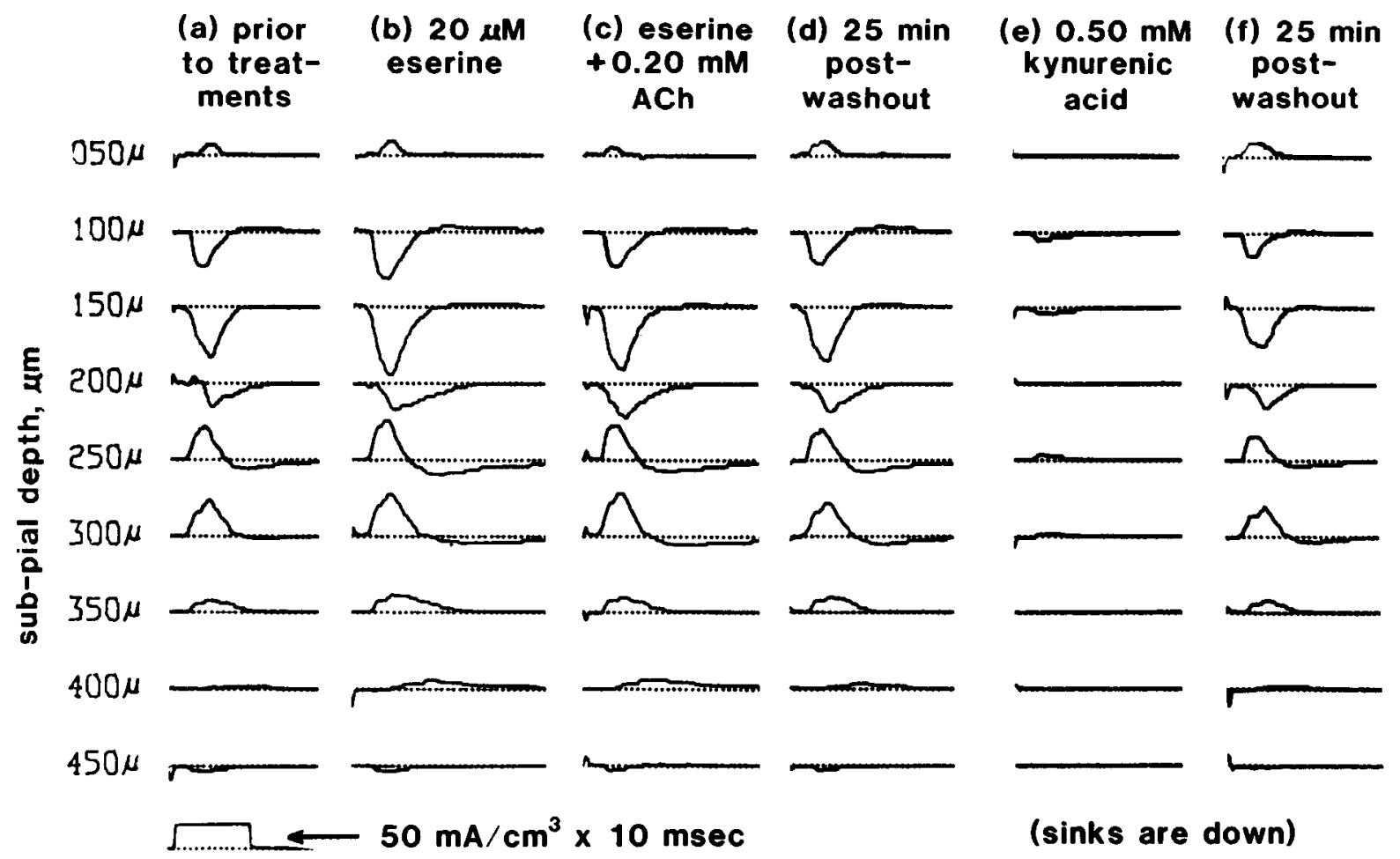

Figure 9. Typical effects of eserine, eserine plus ACh, and kynurenic acid on CSD profiles. All recordings were made from the same preparation and electrode penetration. In relation to the recording of $(a)$ at 0 min, the recording times were $(b) 35,(c) 70,(d) 95,(e) 125$, and $(f) 160$ min, with eserine added at 11, ACh at 46, washout at 72, kynurenic acid at 105, and washout at 134 min. Profile $a$ was recorded 6 hr after dissection.

failed to exceed the amplitude of the shoulder and decayed more slowly than normal from the time at which the shoulder had occurred in the initial responses. Consistent with the hypothesis of Vanegas et al. (1974), this posttreatment $\mathrm{N}$-wave may represent a relatively isolated first-order postsynaptic current,
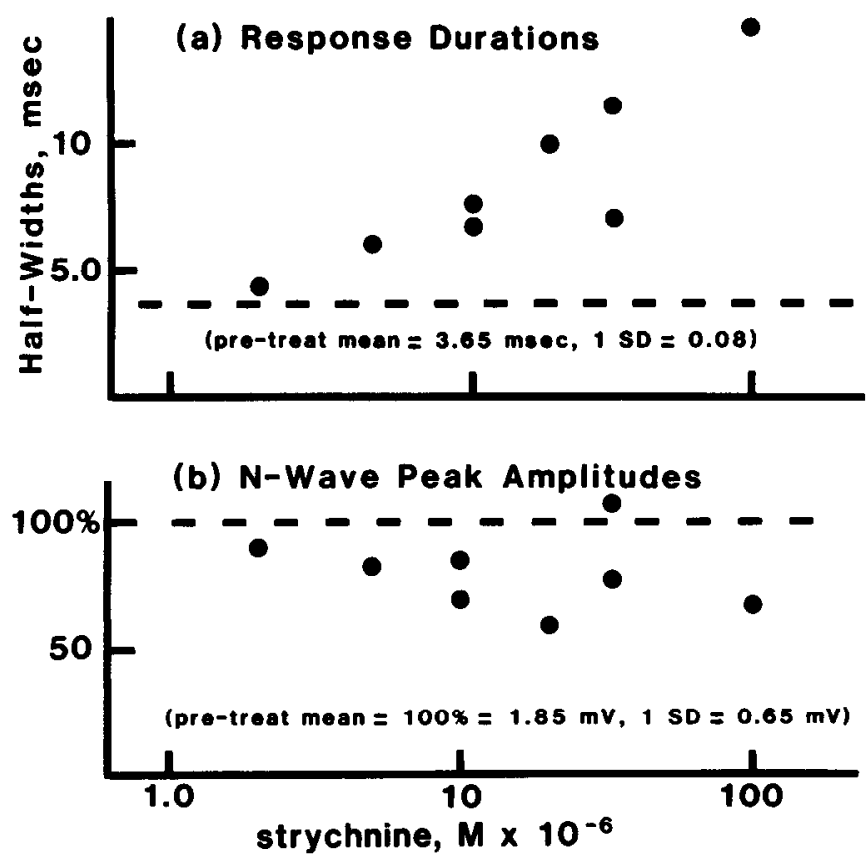

Figure 10. Log concentration-effect curves for strychnine, as in Figure 3; data from 4 experiments. whereas the other traces appear to contain contributions from second-order spikes (Langdon et al., 1985). This pattern suggested that failure to restore pretreatment responscs was due to a loss of excitability of second-order tectal elements as preparations deteriorated. Treatments with high levels of d-TC and strychnine may have accelerated this loss.

\section{Discussion}

These results may be grouped into 4 general observations that pertain to excitatory and inhibitory mechanisms in the tectum. First, field potentials that are generated by monosynaptic excitatory postsynaptic currents (EPSCs) in the tectum following

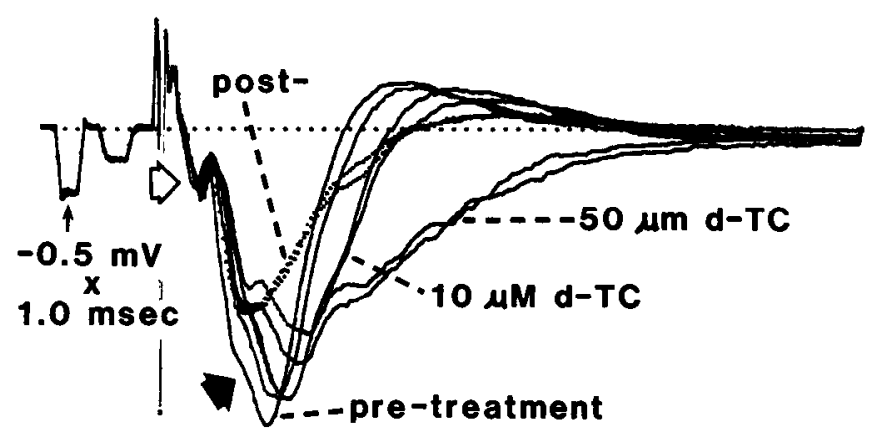

Figure 11. Example typifying those preparations that did not return to the pretreatment response form after washout of d-TC. Two samples were taken at least 5 min apart after at least 20 min of the conditions as labeled, and the average traces are superimposed. The electrode was at $150 \mu \mathrm{m}$ depth and was not repositioned between recordings. The broad unfilled arrow indicates the most prominent presynaptic wave; the filled arrow points to a shoulder that may result when there is a pause between first- and second-order contributions to the $\mathrm{N}$-wave. 
optic tract stimulation wcre not significantly reduced in amplitude by the presence of a variety of specific nicotinic or more general cholinergic ligands at concentrations that abolish transmission in all well-characterized nicotinic or cholinergic systems. Second, 2 substances, d-TC and strychnine, which share the ability to antagonize some amino acid-mediated inhibitory neurotransmission system(s), markedly prolonged the time course of these field potentials and, to a lesser degree, reduced their peak amplitudes. Third, there may be a cholinergic system that can enhance excitatory retinotectal transmission, at least in vitro. Fourth, the activity of kynurenic acid suggests that there is a major role in fish retinotectal transmission played by neurotransmission involving glutamate or related acidic amino acids. Finally, there are 2 methodological issues that deserve comment.

\section{Assumptions employed in interpretation}

Our interpretation of the results has been based on 4 assumptions. The first of these is that waves 1 and 2 of the field potentials are predominantly generated by EPSCs in dendrites that are directly postsynaptic to optic nerve terminals. This assumption has been extensively discussed in the literature both as specifically concerns tectal field potentials (e.g., Chung et al., 1974; Schmidt, 1979; Vanegas, 1983; Langdon et al., unpublished observations), as well as similar field potentials in many other vertebrate "open field" neuronal systems (e.g., Llinás et al., 1969; Nicholson and Llinás, 1971; Haberly and Shepherd, 1973; Andersen et al., 1978). There appears to be general agreement that at least the initial portions of waves 1 and 2 represent a first-order postoptic nerve fiber EPSC. However, the peak of waves 1 and 2 and all of wave 3 may be contributed to by second-order impulse activity in tectal neurons (Vanegas et al., 1974; Sajovic and Levinthal, 1983; Vanegas, 1983). If this is correct, then the time course and amplitude of waves 1 and 2 also depend on the excitability of second-order tectal neurons, and not just on the efficacy of excitatory retinotectal transmission. By this hypothesis, the delay in the peaks of waves 1 and 2 and the modest decreases in peak amplitude that occurred during d-TC and strychnine may reflect delay and desynchronization of second-order impulses. This hypothesis can also explain why larger responses exhibit sharper rise, fall, and overshoot, and suggests that effects on postoptic nerve fiber EPSCs in the tectum might be isolated and quantified more precisely in low $\left[\mathrm{Ca}^{2+}\right] /$ high $\left[\mathrm{Mg}^{2+}\right]$ media (Langdon et al., 1985; Langdon and Freeman, 1986).

A second assumption is that the field potentials observed here in vitro were similar in origin to those previously elicited by optic nerve stimulation in vivo (e.g., Schmidt, 1979; Schmidt and Freeman, 1980). With this present in vitro experimental system, the possibility must be considered that stimulation could have been unintentionally delivered directly to tectal neurons or to other afferents besides optic fibers (such as marginal fibers). We are convinced, however, that only optic fibers were stimulated because (1) using a glass micropipette as the stimulating electrode, the snug placement of the stump of the optic tract in the orifice of the stimulating pipette was unambiguous; (2) low stimulus voltages were used, with maximal responses generally observed above $2 \mathrm{~V}$; and (3) the field potentials and CSD profiles almost exactly duplicated in amplitude and time course those observed in previous studies, both in vivo (Schmidt, 1979; Schmidt and Freeman, 1980) and in vitro (Matsumoto and Bando, 1981; Teyler et al., 1981). To be precise, only those field potentials observed in vitro with the pial-side-down orientation exhibited amplitudes typical of those in previous in vivo studies (e.g., Schmidt and Freeman, 1980). However, this was expected because only this particular orientation duplicated the geometry of extracellular conductivity that existed in the prior studies, placing a nonconducting boundary in opposition to the pial surface. (In the prior studies, the nonconductor was air.)

The observed responses did not resemble field potentials elicited by stimulation of marginal fibers (Vanegas et al., 1979) and were distinct from responses elicited when the stimulating pipette orifice was lodged directly against the tectum (not shown). Among other distinctions, responses to optic tract stimulation exhibited a sharp threshold as stimulus strength was varied, and the "maximal response" pattern was unvarying over a 2-fold increase in stimulus strength. In contrast, responses to direct tectal stimulation varied continuously with varying stimulus strength. Because the cut ends of the optic fibers were lodged, collectively, in the pipette orifice, anodal current to the pipette would be expected to be the most effective means of eliciting their depolarization, as was observed.

The third assumption is that the test substances placed in the bath gained access to the retinotectal synapses, so that concentrations at these synapses were eventually close to or equal to those in the bath. The data support this assumption in several ways. Specifically, (1) d-TC affected response durations in the present study very much as it did in 2 previous studies (Stevens, 1973; Schmidt and Freeman, 1980), but subpial injection of 1 mM d-TC was necessary to produce about the same effect as observed at present with $50-160 \mu \mathrm{M}$ in the bath. (2) In vitro the effects of bath-applied d-TC, strychnine, and kynurenic acid began within 5-10 min and stabilized by or before $30 \mathrm{~min}$. Both strychnine and $\mathrm{d}-\mathrm{TC}$ are charged species and relatively large compared to carbachol, nicotine, ACh, TMA, and mecamylamine. Lophotoxin is uncharged, nonpolar, and, solubilized in DMSO, would be expected to permeate most diffusion barriers quickly. (3) The concentration dependencies of the actions of bath-applied $\mathrm{Ca}^{2+}$ and $\mathrm{Mg}^{2+}$ mirrored those in classically studied in vitro synaptic systems (reviewed by Katz, 1969; Hubbard, 1973; Krnjević, 1974; see also Dingledine and Somjen, 1981), and equilibration to new levels of these cations was complete in 15-30 min (Langdon et al., unpublished observations). (4) The enhancement of field potentials by carbachol and eserine began in 2-5 min. (5) Finally, recordings were made from loci only $200-300 \mu \mathrm{m}$ from the cut edge of the sections. Even if the pial surface was impermeable, test substances should have equilibrated via this cut margin or via the ventricular margin.

These arguments are compelling as regards the inaction of the small nicotinic ligands tested but are not so convincing when interpreting the inaction of $\alpha$-BTX. However, $10 \mathrm{hr}$ of exposure to the latter would be expected to overcome considerable barriers to diffusion. Consistent with this assertion, dense binding of ${ }^{125} \mathrm{I}-\alpha$-BTX in the optic neuropil was previously observed 24 $\mathrm{hr}$ after intraventricular injection in vivo (Oswald et al., 1980).

The fourth assumption is that the substances and concentrations used in these experiments would have blocked any known nicotinic or otherwise cholinergic transmission system. All of the pharmacological treatments employed-except for strychnine, eserine, and kynurenic acid-have been shown to block either neuromuscular or autonomic nicotinic transmission or both (Fatt and Katz, 1951; Paton and Perry, 1953; Thesleff, 1955; Eccles, 1956; Blackman et al., 1963; Ginsborg and Guerrero, 1964; Payton, 1966; Koketsu, 1969; Miledi and Potter, 
1971; Ascher et al., 1979; Langdon and Jacobs, 1983, 1985). Furthermore, their efficacy was verified by assay in appropriate peripheral systems. It should be noted that either desensitization of receptors or steady depolarization by the cholinergic agonists used would be expected to abolish any transient field potentials that depended upon nicotinic transmission.

\section{Cholinergic transmission}

Since these assumptions appear to be valid, we have concluded that monosynaptic excitatory retinotectal transmission does not depend directly upon nicotinic or other cholinergic receptors, as these are known to exist from studies of neurotransmission in the PNS. This conclusion gives rise to 4 related questions: (1) Do other present data support or conflict with this conclusion? (2) Does nicotinic or, more generally, cholinergic neurotransmission play any role in the optic tectum? (3) What is the function of the tectal protein that closely resembles the neuromuscular $\mathrm{nAChR}$ by biochemical and immunological criteria? (4) Finally, what was the mechanism whereby nicotinic antagonists altered optically evoked field potentials and retinotopic order of the optic projection in previous in vivo experiments?

Concerning question (1), recent histochemical data are consistent with the present physiological results, mitigating against a primary role for $\mathrm{ACh}$ in monosynaptic retinotectal transmission. Immunoreactivity with antibodies to ChAT is present in the optic neuropil but is not much affected by enucleation (Ricciuti and Gruberg, 1985; Ross and Godfrey, 1986; Tumosa and Stell, 1986; Tumosa et al., 1986). The major portion of ChAT in the tectal neuropil is therefore present in structures other than optic fiber terminals. Antibodies to the nAChR (from fish electric organ) have recently been applied to verify that the $\mathrm{nAChR}$, or some closely related protein, is present in the optic neuropil (Sargent et al., 1984; Henley et al., 1986a, b), as earlier biochemical studies had indicated (Oswald and Freeman, 1979, 1981; Oswald et al., 1980). These immunologic data imply that this protein of the fish optic tectum is closely related to the neuromuscular and electric organ $\mathrm{nAChR}$, and recent amino acid sequence data of Conti-Tronconi et al. (1985) suggest that the same is true in chick tectum and the rest of the chick brain. However, histochemical localization of anti-nAChR antibody binding on the ultrastructural level (P. B. Sargent, personal communication) and comparison of the amounts of antibody-bound protein after ${ }^{3} \mathrm{H}$-methionine was injected either into the tectum or the eye (Henley et al., 1986b) have indicated that the $\mathrm{nAChR}$ in goldfish tectum is located in the optic fiber terminals only.

The presence of presynaptic nAChR and of ChAT in projections to the superficial optic neuropil suggests the possibility that a nicotinic or other cholinergic system serves to modulate the release of excitatory transmitter from optic fiber terminals. This hypothesis is further supported by recent observations of field potentials in the goldfish tectum in low $\left[\mathrm{Ca}^{2+}\right]$ media following closely paired stimulations of the optic tract (P. B. Manis and J. A. Freeman, unpublished observations). The carbachol and eserine actions reported here also suggest the presence of a cholinergic modulatory system but do not weigh strongly for (or against) the presence of modulation that is specifically nicotinic, because desensitization to the effects of these agonists occurred much more slowly than would be expected based on studies of other nicotinic systems (Paton and Perry, 1953; Thesleff, 1955).

The existence of such a modulatory system could partly explain the apparent discrepancy between the presently observed inaction of nicotinic antagonists and their efficacy in previous in vivo studies, in which topical applications or injections of these substances were followed by a $>80 \%$ drop in response amplitudes (Freeman, 1977; Freeman et al., 1980; Schmidt and Freeman, 1980; Schmidt, 1985). Ricciutti and Gruberg (1985) have shown that, in frogs, virtually all of the ChAT activity in the optic neuropil is in the arbors of projections extrinsic to the tectum (from the nucleus isthmus). It is possible that this cholinergic input somehow functions to enable retinotectal transmission, but such a hypothesis must somehow account for the present observation that, in isolation, retinotectal transmission can proceed without such enabling.

\section{Spreading depression}

The possibility should be considered that the micropressure injection method employed in previous studies in situ produced subtle nonspecific effects that were difficult to distinguish from specific pharmacological effects. For example, it is possible that spreading depression-like episodes, as were observed here in vitro, may also occur in vivo. Furthermore, it is plausible that the process of pressure injection of relatively large volumes would induce such episodes and that these may last longer in vivo than they do in isolated sections of tectum. The injected volumes were approximately $2 \mu \mathrm{l}$, which is equal to the entire volume (intracellular space included) of a cylinder through the tectum $2.4 \mathrm{~mm}$ in diameter (assuming a width of $450 \mu \mathrm{m}$ ). Such injections might create mechanical trauma and/or hypoxia sufficient to generate depression, and the circulatory system might require considerable time to clear such a volume from the extracellular space. In vitro spreading depression-like episodes could be readily distinguished from transmission block only because they ended spontaneously, despite continuation of drug treatment. However, the effects of in situ drug injections are transient themselves, so it would be quite difficult to distinguish between cessation of a spreading depression episode (presumably by clearing the extracellular space of excess $\mathrm{K}^{+}$) and the end of action by a test substance because it was cleared from the extracellular compartment.

While it is true that, by this hypothesis, control injections should have also produced depression, it is also possible that the effect of injections depended upon subtle factors which could not be adequately controlled. It is noteworthy that not all of the previous in situ data support the hypothesis that transmission is nicotinic. Besides the inconsistencies in d-TC and nicotine results mentioned in the introduction, responses were much reduced after eserine injections (Schmidt and Freeman, 1980), but eserine does not block other nicotinic systems (e.g., Thesleff, 1955). Also, the lack of effect by bicuculline when applied in this manner (Schmidt and Freeman, 1980) has not been consistent with later results (Sajovic and Levinthal, 1983; Manis and Freeman, 1985).

\section{Tectal nAChRs and retinotopic order}

Focal application of $\alpha$-BTX has been shown to induce fine rearrangements of retinal terminals in the tectal neuropil (Freeman, 1977; Schmidt, 1985). Schmidt has proposed (1985) that $\alpha$-BTX interferes with activity-dependent fine tuning of retinotopic order via antagonism of nAChRs on tectal neurons. More consistent with present data, $\alpha$-BTX may interfere with such fine tuning by antagonizing retinotectal transmission presynaptically. However, the nature and extent of this antagonism remains poorly understood, and current data also raise the possibility 
that the toxin may act directly on optic terminals and alter their positions via some mechanism that is unrelated to the efficacy of retinotectal transmission.

\section{Excitatory amino acid transmitters}

The above analysis leaves open the long-standing question as to what neurotransmitter(s) is (are) directly responsible for mediating fast excitatory retinotectal transmission? The antagonism by kynurenic acid offers preliminary evidence supporting a primary role for excitatory amino acids, which have previously been proposed to have this function on the basis of histochemical and biochemical evidence (reviewed by Freeman and Norden, 1984). Recent data indicate that 0.5-1.0 mM kynurenic acid greatly reduces fast depolarizations elicited by putative amino acid neurotransmitters such as glutamate and $N$-methylD-aspartate (Perkins and Stone, 1982; Jahr and Jessell, 1985). Furthermore, some specificity in this action has been shown, in that the same treatments do not interfere with Renshaw cellmediated inhibition of spinal motor neurons (Jahr and Yoshio$\mathrm{ka}, 1986$ ), which is believed to require both intact glycinergic and nicotinic receptors. We have recently made additional observations with kynurenic acid and 2 related antagonists that support the hypothesis that a glutamate or glutamate-related receptor plays an essential role in fast excitatory retinotectal transmission (Langdon and Freeman, 1986).

\section{A tectal inhibitory circuit}

The data presented here also pertain to second-order inhibitory mechanisms in the tectum. Injections of d-TC or strychnine into the tecta of goldfish, zebrafish, or frogs have produced (1) spike bursts and erratic spiking (Stevens, 1973; Sajovic and Levinthal, 1983); (2) decreases in field potential amplitudes following spike bursts and failure of lateral inhibition (Stevens, 1973); (3) prolongation of field potentials with the disappearance of response wave 3 (the late overshoot) (Stevens, 1973; Schmidt and Freeman, 1980; Sajovic and Levinthal, 1983). Moreover, d-TC has long been known to be epileptogenic (e.g., Hill et al., 1972). Stevens (1973) has proposed the existence of a tectal inhibitory system depending upon nicotinic transmission. Based on similar effects of d-TC, Caston and Roussel (1984) have recently proposed that a similar system exists in the frog semicircular canal. The present data, as well as studies by Lebeda et al. (1982), have confirmed the disinhibitory action of d-TC but have also shown that this effect is not shared by other nicotinic antagonists. It is clear, therefore, that demonstration of a disinhibitory action by d-TC alone does not provide compelling evidence for the existence of an inhibitory nicotinic systcm.

Scholfield (1982) has cautioned that the specificities of both $\mathrm{d}-\mathrm{TC}$ and strychnine may have been overrated. Block of putative glycine receptors has been reported at low micromolar concentrations of strychnine (review by Marc, 1985), but strychnine appears to block some other systems as well, most notably some GABA receptors (review by Snodgrass, 1983). It has been shown that d-TC directly inhibits responses to both glycine and GABA in cat spinal cord (Curtis et al., 1974), GABA-mediated inhibition in guinea pig hippocampal slices (Lebeda et al., 1982), and GABA actions on olfactory cortex slices (Scholfield, 1982). Prolongation of tectal field potentials by d-TC is probably due to a direct block of inhibitory neurotransmission involving an amino acid such as glycine, GABA, taurine, or $\beta$-alanine. The present physiological data suggest that inhibitory systems act both in the optic neuropil and deeper, and do not offer grounds for ruling out actions by any specific inhibitory neurotransmitter-receptor system.

Suggesting the importance of a GABAergic system, response prolongations similar to those reported here have been observed by Sajovic and Levinthal (1983) after injection of bicuculline or picrotoxin into zebrafish tectum, and by Manis and Freeman (1985) during in vitro application of bicuculline to goldfish tectal slices. Since either glycinergic or GABAergic inhibition have often appeared to act via increases in $\mathrm{Cl}^{-}$permeability (reviewed by Krnjević, 1974; Nistri and Constanti, 1979; Snodgrass, 1983), it seems significant that response prolongations resembling those reported were observed during in vitro incubations in $\mathrm{Cl}^{-}$-deficient medium (Matsumoto and Bando, 1981) and Hardy et al. (1984) have recorded IPSPs intracellularly in pigeon tectum that invert after intracellular $\mathrm{Cl}^{-}$injections. Inhibitory feedback loops may be a fundamental component in the organization of many, or most, vertebrate local neuronal circuits (Shepherd, 1979), and such loops have often been observed during intracellular recording as EPSPs cut short by IPSPs. EPSP-IPSP sequences have been observed during intracellular recordings from tectum in carp (Matsumoto et al., 1983), goldfish (Freeman and Norden, 1984), and pigeons (Hardy et al., 1984). In the latter case, most of the IPSPs failed to follow stimulus rates $>5 \mathrm{~Hz}$, suggesting that they were second order. We have observed that waves 1 and 2 are consistently converted to a simpler, exponentially decaying current with a half-width of 4-5 msec in low $\left[\mathrm{Ca}^{2+}\right]$ and/or high $\left[\mathrm{Mg}^{2+}\right]$ (Langdon et al., unpublished observations). These results suggest that high levels of optic fiber activity elicit local second-order inhibitory conductances in the dendrites of the superficial optic neuropil. These conductances reduce the amount of depolarizing current that would otherwise flow to deeper dendrites and neuronal somata.

\section{References}

Andersen, P., H. Silfvenius, S. H. Sundberg, O. Sveen, and H. Wigstrom (1978) Functional characteristics of unmyelinated fibers in the hippocampal cortex. Brain Res. 144: 11-18.

Ascher, P., W. A. Large, and H. P. Rang (1979) Studies on the mechanism of action of acetylcholine antagonists on rat parasympathetic ganglion cells. J. Physiol. (Lond.) 295: 139-170.

Blackman, J. G., B. L. Ginsborg, and C. Ray (1963) Synaptic transmission in the sympathetic ganglion of the frog. J. Physiol. (Lond.) 167: 355-373.

Bolton, T. B. (1972) The depolarizing action of acetylcholine or carbachol in intestinal smooth muscle. J. Physiol. (Lond.) 220: 647-672.

Brown, D. A. (1979) Neurotoxins and the ganglionic (C6) type of nicotinic receptor. In Neurotoxins: Tools in Neurobiology (Adv. Cytopharmacol., Vol. 3), B. Ceccarelli and F. Clementi, eds., pp. 225230, Raven, New York.

Brown, D. A., and L. Fumagalli (1977) Dissociation of alpha-bungarotoxin binding and receptor block in the rat superior cervical ganglion. Brain Res. 129: 165-168.

Buser, P. (1955) Étude de l'activité électrique du lobe optique des vertébrés inférieurs. J. Physiol. (Paris) 47: 737-768.

Caston, J., and H. Roussel (1984) Curare and the efferent vestibular system. Acta Otolaryngol. (Stockh.) 97: 19-26.

Changeux, J.-P., A. Devillers-Thiéry, and P. Chemouilli (1984) Acetylcholine receptor: An allosteric protein. Science 225: 1335-1345.

Chung, S.-H., T. V. P. Bliss, and M. J. Keating (1974) The synaptic organization of optic afferents in the amphibian tectum. Proc. R. Soc. Lond. [Biol.] 187: 421-447.

Clarke, P. B. S., R. D. Schwartz, S. M. Paul, C. B. Pert, and A. Pert (1985) Nicotinic binding in the rat brain: Autoradiographic comparison of $\left[{ }^{3} \mathrm{H}\right]$ acetylcholine, $\left[{ }^{3} \mathrm{H}\right]$ nicotine, and $\left[{ }^{125} \mathrm{I}\right]$-alpha-bungarotoxin. J. Neurosci. 5: 1307-1315.

Cole, A. E., and R. A. Nicoll (1984) Characterization of a slow cholinergic post-synaptic potential recorded in vitro from rat hippocampal pyramidal cells. J. Physiol. (Lond.) 352: 173-188. 
Conti-Tronconi, B. M., S. M. J. Dunn, E. A. Barnard, J. O. Dolly, F. A. Lai, N. Ray, and M. A. Raftery (1985) Brain and muscle nicotinic acetylcholine receptors are different but homologous proteins. Proc. Natl. Acad. Sci. USA 82: 5208-5212.

Curtis, D. R., and J. M. Crawford (1969) Central synaptic transmission-microclcetrode studics. Annu. Rev. Pharmacol. 9: 209-240.

Curtis, D. R., C. J. A. Game, and R. M. McCulloch (1974) Antagonism of inhibitory amino acid action by tubocurarine. Br. J. Pharmacol. 52: 101-103.

Dingledine, R., and G. Somjen (1981) Calcium dependence of synaptic transmission in the hippocampal slice. Brain Res. 207: 218-222.

Duggan, A. W., J. G. Hall, and C. Y. Lee (1976) Alpha-bungarotoxin, cobra neurotoxin and excitation of Renshaw cells by acetylcholine. Brain Res. 107: 166-170.

Eccles, R. M. (1952) Responses of isolated curarized sympathetic ganglia. J. Physiol. (Lond.) 117: 196-217.

Eccles, R. M. (1956) The effect of nicotine on synaptic transmission in the sympathetic ganglion. J. Pharmacol. Exp. Ther. 118: 26-38.

Fatt, P., and B. Katz (1951) An analysis of the end-plate potential recorded with an intra-cellular clectrode. J. Physiol. (Lond.) 115:320370.

Freeman, J. A. (1977) Possible regulatory role of acetylcholine receptor in maintenance of retinotectal synapses. Nature 269: 218-222.

Freeman, J. A., and C. Nicholson (1975) Experimental optimization of current source-density technique: Application to anuran cerebellum. J. Neurophys. 38: 369-383.

Freeman, J. A., and J. J. Norden (1984) Neurotransmitters in the optic tectum of nonmammalians. In Comparative Neurology of the Optic Tectum, H. Vanegas, ed., pp. 469-546, Plenum, New York.

Freeman, J. A., J. T. Schmidt, and R. E. Oswald (1980) Effect of alphabungarotoxin on retinotectal synaptic transmission in the goldfish and the toad. Neuroscience 5: 929-942.

Ganong, A. H., T. H. Lanthorn, and C. W. Cotman (1983) Kynurenic acid inhibits synaptic and acidic amino acid-induced responses in the rat hippocampus and spinal cord. Brain Res. 273: 170-174.

Ginsborg, B. L., and S. Guerrero (1964) On the action of depolarizing drugs on sympathetic ganglion cells of the frog. J. Physiol. (Lond.) 172: 189-206.

Haberly, L. B., and G. M. Shepherd (1973) Current-density analysis of summed evoked potentials in opossum prepyriform cortex. J. Neurophys. 36: 789-802.

Hardy, O., N. Leresche, and D. Jassik-Gershenfeld (1984) Postsynaptic potentials in neurons of the pigeon's optic tectum in response to afferent stimulation from the retina and other visual structures: An intracellular study. Brain Res. 311: 65-74.

Henley, J., M. Mynlieff, J. Lindstrom, and R. E. Oswald (1986a) Interaction of monoclonal antibodies to electroplaque acetylcholine receptors with the alpha-bungarotoxin binding site of goldfish brain. Brain Res. 364: 405-408.

Henley, J., J. Lindstrom, and R. E. Oswald (1986b) Acetylcholine receptor synthesis in retina and transport to optic tectum in goldfish. Science 232: 1627-1629.

Hill, R. G., M. A. Simmonds, and D. W. Straughan (1972) Convulsive properties of d-tubocurarine and cortical inhibition. Nature 240: 5152.

Hubbard, J. I. (1973) Microphysiology of vertebrate neuromuscular transmission. Physiol. Rev. 53: 674-724.

Jackson, H., E. F. Nemeth, and T. N. Parks (1985) Non-N-methylD-aspartate receptors mediating synaptic transmission in the avian cochlear nucleus: Effects of kynurenic acid, dipicolinic acid and streptomycin. Neuroscience 16: 171-179.

Jahr, C. E., and T. M. Jessell (1985) Synaptic transmission between dorsal root ganglion and dorsal horn neurons in culture: Antagonism of monosynaptic excitatory postsynaptic potentials and glutamate excitation by kynurenate. J. Neurosci. 5: 2281-2289.

Jahr, C. E., and K. Yoshioka (1986) Ia afferent excitation of motoneurones in the in vitro new-born rat spinal cord is selectively antagonized by kynurenate. J. Physiol. (Lond.) 370: 515-530.

Katz, B. (1969) The Release of Neurotransmitter Substances, Liverpool U.P., Liverpool, UK.

Koerner, J. F., and C. W. Cotman (1983) A microperfusion chamber for brain slice pharmacology. J. Neurosci. Methods 7: 243-251.

Koketsu, K. (1969) Cholinergic synaptic potentials and the underlying ionic mechanisms. Fed. Proc. 28: 101-1 12.
Konishi, J. (1960) Electric response of visual center of optic nerve stimulation in fish. Jpn. J. Physiol. 10: 28-41.

Krnjević, K. (1974) Chemical nature of synaptic transmission in vertebrates. Physiol. Rev. 54: 418-540.

Langdon, R. B., and J. A. Freeman (1986) Antagonists of glutaminergic ncurotransmission block retinotectal transmission in goldfish. Brain Res. 398: 169-174.

Langdon, R. B., and R. S. Jacobs (1980) An inexpensive frequencymodulated (FM) audio monitor of time-dependent analog parameters. J. Pharmacol. Methods 3: 181-190.

Langdon, R. B., and R. S. Jacobs (1983) Quantal analysis indicates an alpha-toxin-like action by lophotoxin, a non-ionic marine natural product. Life Sci. 32: 1223-1228.

Langdon, R. B., and R. S. Jacobs (1985) Irreversible autonomic actions by lophotoxin suggest utility as a probe for both $\mathrm{C} 6$ and $\mathrm{C} 10$ nicotinic receptors. Brain Res. 359: 233-238.

Langdon, R. B., J. S. Andrews, and J. A. Freeman (1985) In vitro assessment of proposed nicotinic mechanisms in goldfish optic tectum. Invest. Ophthalmol. Vis. Res. Suppl. 26: 106.

Lebeda, F. J., J. J. Hablitz, and D. Johnston (1982) Antagonism of GABA-mediated responses by d-tubocurarine in hippocampal neurons. J. Neurophysiol. 48: 622-632.

Llinás, R., C. Nicholson, J. A. Freeman, and D. E. Hillman (1969) Reply to technical comment by W. H. Calvin and D. Hellerstein, "Dendritic spikes versus cable properties." Science 163: 97.

Manis, P. B., and J. A. Freeman (1985) Optical recordings of neural activity in the goldfish optic tectum. Invest. Ophthalmol. Vis. Sci. Suppl. 26: 264.

Marc, R. E. (1985) The role of glycine in retinal circuitry. In Retinal Transmitters and Modulators: Models for the Brain, W. W. Morgan, ed., pp. 119-158, CRC Press, Boca Raton, FL.

Matsumoto, N., and T. Bando (1981) Long-lasting evoked potential and repetitive firing recorded from the carp optic tectum in Cl-deficient medium in vitro. Brain Res. 225: 437-441.

Matsumoto, N., H. Kiyama, and T. Bando (1983) An intracellular study of the optic tectum of the carp in vitro. Neurosci. Lett. 38: 1722.

Meek, J. (1983) Functional anatomy of the tectum mesencephali of the goldfish. Brain Res. Rev. 6: 247-297.

Miledi, R., and L. T. Potter (1971) Acetylcholine receptors in muscle fibers. Nature 233: 599-603.

Morley, B. J., and G. E. Kemp (1981) Characterization of a putative nicotinic acetylcholine receptor in mammalian brain. Brain Res. Rev. 3: 81-104.

Nicholson, C., and R. Llinás (1971) Field potentials in the alligator cerebellum and theory of their relationship to Purkinje cell dendritic spikes. J. Neurophysiol. 34: 509-531.

Nistri, A., and A. Constanti (1979) Pharmacological characterization of different types of GABA and glutamate receptors in vertebrates and invertebrates. Prog. Neurobiol. 13: 117-235.

Oswald, R. E., and J. A. Freeman (1979) Characterization of the nicotinic acetylcholine receptor isolated from goldfish brain. J. Biol. Chem. 254: 3419-3426.

Oswald, R. E., and J. A. Freeman (1981) Alpha-bungarotoxin binding and central nervous system nicotinic acetylcholine receptors. Neuroscience $6: 1-14$.

Oswald, R. E., J. T. Schmidt, J. J. Norden, and J. A. Freeman (1980) Localization of alpha-bungarotoxin binding sites in the goldfish retinotectal projection. Brain Res. 187: 113-127.

Paton, W. D. M., and W. L. M. Perry (1953) The relationship between depolarization and block in the cat's superior cervical ganglion. J. Physiol. (Lond.) 119: 43-57.

Paton, W. D. M., and E. J. Zaimis (1949) The pharmacological actions of polymethylene bis-trimethylammonium salts. Br. J. Pharmacol. 4: $381-400$.

Patrick, J., and B. Stallcup (1977a) Alpha-bungarotoxin binding and cholinergic receptor function on a rat sympathetic nerve line. J. Biol. Chem. 252: 8629-8633.

Patrick, J., and B. Stallcup (1977b) Immunological distinction between acetylcholine receptor and the alpha-bungarotoxin binding component on sympathetic neurons. Proc. Natl. Acad. Sci. USA 74: 46894692.

Payton, B. W. (1966) Use of the frog neuromuscular junction for 
assessing the action of drugs affecting synaptic transmission. Br. J. Pharmacol. Chemother. 28: 35-43.

Perkins, M. N., and T. W. Stone (1982) An inntophoretic investigation of the actions of convulsant kynurenines and their interaction with the endogenous excitant quinolinic acid. Brain Res. 247: 184187

Rall, W. (1967) Distinguishing theoretical synaptic potentials computed for different soma-dendritic distributions of synaptic input. J. Neurophys. 30: 1138-1168.

Ricciuti, A. J., and E. R. Gruberg (1985) Nucleus isthmus provides most tectal choline acetyltransferase in the frog Rana pipiens. Brain Res. 341: 399-402.

Ross, C. D., and D. A. Godfrey (1986) Effect of enucleation on choline acetyltransferase activity in layers of goldfish optic tectum. Brain Res. 373: 49-56.

Sajovic, R., and C. Levinthal (1983) Inhibitory mechanism in zebrafish optic tectum: Visual response properties of tectal cells altered by picrotoxin and bicuculline. Brain Res. 27: 227-240.

Sargent, P. B., S. H. Pike, L. Tsavaler, and J. M. Lindstrom (1984) Monoclonal antibodies to electric organ acetylcholine receptor bind to frog optic tectum. Soc. Neurosci. Abstr. 10: 935.

Schmidt, J. T. (1979) The laminar organization of optic nerve fibers in the tectum of goldfish. Proc. R. Soc. London [Biol.] 205: 287-306.

Schmidt, J. T. (1985) Apparent movement of optic terminals out of a local postsynaptically blocked region in goldfish tectum. J. Neurophysiol. 53: 237-251.

Schmidt, J. T., and J. A. Freeman (1980) Electrophysiological evidence that retinotectal synaptic transmission in the goldfish is nicotinic cholinergic. Brain Res. 187: 129-142.

Scholfield, C. N. (1982) Antagonism of gamma-aminobutyric acid and muscimol by picrotoxin, bicuculline, strychnine, bemegride, leptazol, d-tubocurarine, and theophylline in the isolated olfactory cortex. Naunyn Schmiedebergs Arch. Pharmacol. 318: 274-280.

Shepherd, G. M. (1979) The Synaptic Organization of the Brain, Oxford U.P., New York.
Snodgrass, S. R. (1983) Receptors for amino acid transmitters. In Biochemical Studies of CNS Receptors, L. L. Iversen, S. D. Iversen, and S. H. Snyder, eds., pp. 167-239, Plenum, New York.

Snow, R. W., C. P. Taylor, and F. E. Dudek (1983) Electrophysiological and optical changes in slices of rat hippocampus during spreading depression. J. Neurophysiol. 50: 561-572.

Stevens, C. F. (1985) AChR structure: A new twist in the story. Trends Neurosci. 8: 1-2.

Stevens, C. N. (1973) A cholinergic inhibitory system in the frog optic tectum: Its role in visual electrical responses and feeding behavior. Brain Res. 49: 309-321.

Teyler, T. J., P. Lewis, and V. E. Shashova (1981) Neurosphysiological and biochemical properties of the goldfish optic tectum maintained in vitro. Brain Res. 7: 45-56.

Thesleff, S. (1955) The mode of neuromuscular block caused by acetylcholine, nicotine, decamethonium, and succinylcholine. Acta Physiol. Scand. 34: 218-231.

Tumosa, N., and W. K. Stell (1986) Choline acetyltransferase-immunoreactivity suggests that ganglion cells in the goldfish retina are not cholinergic. J. Comp. Neurol. 244: 267-275.

Tumosa, N., W. K. Stell, C. D. Johnson, and M. L. Epstein (1986) Putative cholinergic interneurons in the optic tectum of goldfish. Brain Res. 370: 365-369.

Vanegas, H. (1983) Organization and physiology of the teleostean optic tectum. In Fish Neurobiology, Vol. 2, R. E. Davis and R. G. Northcutt, eds., pp. 43-90, University of Michigan Press, Ann Arbor, MI.

Vanegas, H., J. Amat, and E. Essayag-Millan (1974) Postsynaptic phenomena in optic tectum neurons following optic nerve stimulation in fish. Brain Res. 77: 25-38.

Vanegas, H., B. Williams, and J. A. Freeman (1979) Responses to stimulation of marginal fibers in the teleostean optic tectum. Exp. Brain Res. 34: 335-349. 